Idle chatter or compelling conversation? The potential of the social media-based \#NGSSchat network for supporting science education reform efforts

\author{
Joshua M. Rosenberg, University of Tennessee, Knoxville \\ Joshua W. Reid, Middle Tennessee State University \\ Elizabeth Dyer, Middle Tennessee State University \\ Matthew Koehler, Michigan State University \\ Christian Fischer, University of Tübingen \\ Thomas J. McKenna, Boston University
}

Author note. Correspondence regarding this article may be directed to Joshua M. Rosenberg (jmrosenberg@utk.edu), 420 Claxton Complex, 1122 Volunteer Blvd., Knoxville, TN 37996. Analytic code and information about how to access the data used in this study are available in an Open Science Framework repository: https://osf.io/9ex7k/.

Author's final pre-print for:

Rosenberg, J. M., Reid, J., Dyer, E., Koehler, M. J., Fischer, C., \& McKenna, T. J. (2020). Idle chatter or compelling conversation? The potential of the social media-based \#NGSSchat for supporting science education reform efforts. Journal of Research in Science Teaching. https://onlinelibrary.wiley.com/doi/10.1002/tea.21660 


\begin{abstract}
The Next Generation Science Standards (NGSS) chat (\#NGSSchat) is a social media-based professional network used to discuss topics related to the NGSS in the United States. While successful reforms involve and coordinate the work of multiple stakeholders, recent research points out a striking lack of coordination between the individuals working in different educational roles - to the detriment of intended changes in the system. In this study, we analyzed more than 7,000 posts from individuals participating in \#NGSSchat on Twitter $(n=247)$ during two years of one-hour synchronous discussions. We studied the depth and types of conversations that took place, the extent to which the involvement of teachers, administrators, researchers, and organizations was balanced, and what explains participation in the network over time. Using a mixed-methods approach involving social network analysis, we found that conversations were primarily transactional, or social, and substantive, or providing opportunities for sense-making about the standards and for participants to transform their practice and that individuals from diverse roles participated, with teachers comprising the plurality of those involved. Additionally, researchers, administrators, and teachers were the most active in the network, with no differences in both initiating, or sending, and being the recipients of, or receiving, replies as a part of conversations. Finally, we found that being a teacher or administrator, as well as receiving replies from individuals who were important in the network, were positively related to sustained participation in the network in the following year. We discuss how \#NGSSchat - as a social media-based professional network - demonstrates similar features in other effective networks, and how social media-based networks invite new visions for how to implement ambitious, largescale changes in science education.
\end{abstract}




\section{Idle chatter or compelling conversation? The potential of the social media-based \#NGSSchat network for supporting science education reform efforts}

Many large-scale educational reform efforts, such as the Next Generation Science Standards (NGSS) in the United States (U.S.), are intended to shift classroom practice. The successful implementation of such efforts requires ambitious changes across more than individual classrooms: changes that involve coordinated efforts across educational systems (National Research Council [NRC], 2015). This systems-level perspective recognizes that an exclusive focus on teachers as individual change agents will likely be insufficient to support policy implementation (Coburn, 2001; Penuel et al., 2015). Instead, supporting reform efforts requires capacity-building for multiple stakeholders, such as that of administrators and instructional coaches as well as teachers (Anderson et al., 2018; Lowenhaupt \& McNeill, 2019), and the collective participation between (and coordination among) multiple stakeholders (Penuel et al., 2013.; Stiles et al., 2017). For example, Stiles et al. (2017) argue that the shifts called for in the NGSS are supported by six drivers, or key factors, including: (1) standards; (2) curriculum, instruction, and achievement; (3) policies; (4) stakeholders; (5) funding; and (6) professional learning. Each of these six drivers cut across different individuals and spheres of the educational system, such as when funding-related decisions require coordination among leaders at the state, district, and school levels.

Despite success in targeting specific stakeholders like teachers or school administrators (Lowenhaupt \& McNeill, 2019; Sandoval et al., 2018), previous large-scale reform efforts in education have struggled to support learning and sustained coordination across stakeholders and components of the educational system (Cobb et al., 2018; Penuel et al., 2011; Peurach et al., 2019; Windschitl, 2006). Research that takes a systems approach to educational reform demonstrates the importance of professional networks for this learning and coordination and has identified the role that networks play in how educational reforms are made sense of and taken up over time (e.g., Coburn et al., 2012; Penuel et al., 2018; Spillane et al., 2012).

While networks contribute to educational reform efforts, less is known about how these contributions occur. In light of the use of social media for both personal and professional reasons, it is crucial to understand the characteristics of these networks, as they may differ from in-person professional networks in important ways that have the potential for-but also challenges related to supporting - systems-wide reforms.

In this study, we explored the extent to which the \#NGSSchat network may contribute to educational reform efforts as a professional network focused on learning and sharing resources about NGSS. This network has regularly met using synchronous Twitter chats to discuss improving science education. Even though \#NGSSchat has the potential to exhibit features of networks that support educational reform efforts, we do not yet understand the extent to which it or other, informal, digital technology-based networks in education do. This study, then, examines two years of these approximately bi-weekly chats in terms of their content, interactions between participants, and participants, including how sustained their participation is. This analysis can help shed light on the role of online professional networks as a component of the broader science education digital ecology in which science education policy is being shaped and implemented.

\section{Literature Review}

We focus on three features of online professional networks, and \#NGSSchat specifically, that have the potential for supporting coordination across educational systems necessary for successful reform implementation:

1. foster substantive conversations (van Bommel et al., 2020); 
2. be accessible to and foster balanced participation among educational stakeholders from different professional roles (Macià \& Garcia, 2016; Rosenberg et al., 2016a; Spillane et al., 2015), instead of involvement dominated by one or two professional roles;

3. sustaining participation in online networks (Greenhow et al., 2019). In the sections below, we explore prior research related to each of the features.

\section{Substantive Conversations}

Participation in conversations is an important form of professional learning and sensemaking about educational reforms (Coburn, 2001; Rosebery \& Warren, 2008; Rosebery et al., 2010), especially when ideas about reforms are situated in the context and problems of practice that practitioners face (Horn \& Little, 2010; Penuel et al., 2013) and are carefully facilitated (Andrews-Larson et al., 2017). These considerations are important in light of research showing that while some social media-based professional networks are distinguished by conversations that evidence learning (van Bommel et al., 2020), others seem to be more superficial (Staudt Willet, 2019). While there is research on conversations that take place between students in K-12 settings (e.g., Michaels \& O'Connor, 2012), and on the role of conversations in face-to-face professional contexts and networks for teachers (Coburn et al., 2010; Horn \& Little, 2010; Horn et al., 2020; Little \& Horn, 2007), less attention has been given to the types of conversations in technology-based professional networks, the first key feature we discuss.

In the context of mathematics and English language learning groups on the social media platform Facebook, van Bommel et al. (2020) explored what subject-specific conversations took place, finding that the majority of conversations provided some opportunity for learning and that a smaller percentage evidenced transformations, or changes, in an individual's knowledge. van Bommel et al. referred to the former type of conversation as transactional, and the latter as transformational. A transactional interaction refers to those in which participation or learning is acknowledged. For instance, they are characterized by an explicit, verbal acknowledgment of something that is shared, or an implicit recognition, such as through a "like" or "favorite" through a social media platform. Differently, transformational conversations were longer and were characterized by turns in the conversation that made clear that the individualsteachers - considered some aspect of planning or teaching differently as a result of what others shared with them.

van Bommel et al. (2020) noted that not only deep (transformational) conversations are important, but also those that are more social in nature. Transformational conversations are not necessarily superior to others for all purposes: Cultivating a sense of belonging, which might be facilitated by transactions, are key goals or parts of professional learning communities (Goode et al., 2014; Putnam \& Borko, 2000, Shulman \& Sherin, 2004) and digital technology-based networks (Greenhalgh et al., 2016; Bucher \& Fiseler, 2017; Lantz-Andersson et al., 2018; Trust et al., 2016). Doing so might involve social conversations that help individuals to feel recognized and may, therefore, play a role in professional networks, particularly with respect to building and maintaining relationships (Greenhalgh et al., 2016; Carpenter \& Krutka, 2014b; Weseley, 2013). Therefore, we view not only transformational conversations as important in dig-based contexts for professional learning but also as an important type of conversation in social media-based contexts for professional learning, particularly when also accompanied by those that are more focused on science education content.

To foster substantive conversations, informal, technology-based professional networks should have specific features, with moderation being one important design element. Moderation is essential for productive conversations to occur (Andrews-Larson et al., 2017) and for 
individuals to have opportunities to share what they have distinct knowledge about (Farrell et al., 2019). If there are active moderators who provide structure to the participation of those involved in the community, such as by organizing chats with questions related to a common theme (Carpenter \& Krutka, 2014a; Greenhalgh et al., 2020). Such moderation is a feature of \#NGSSchat, which has been described as being organized around carefully selected topics related to "all things NGSS, from the research that went into the A Framework $K-12$ for Science Education [sic] to examples of implementation from states and districts already putting the standards into practice" (Shelton \& Ende, 2015, p.3). A benefit of moderation is that while social media-based networks can be facilitated and organized, participants can respond however they choose, perhaps highlighting, for example, issues that emerge in practice that were not anticipated by the authors of reform documents and the standards, which may provide opportunities for collaborative sense-making about the nature of the new science standards (Rosebery et al., 2010). For these reasons, \#NGSSchat may support participants to make sense of science education reform efforts; to better understand how they can coordinate their efforts; and how they are changing what they do - as a teacher, administrator, or even researcher - as a result.

\section{Balanced Participation Among Multiple Stakeholders}

In organizations and systems - including those in education (Frank et al., 2004)—work is divided between individuals in different roles. For example, when researchers and non-profit organizations develop curricula, instructional coaches support their teachers, and teachers adapt and shape what they are exposed to in professional development for their practice. While this facilitates specialization - which can be positive for organizations - recent research points out a striking lack of coordination between the individuals working in different roles in education (Cherbow et al., 2020; Coburn \& Stein, 2010; Peurach et al., 2019; Penuel et al., 2011) — to the detriment of intended changes in the system (Farrell et al., 2019; Stein \& Coburn, 2008).

Therefore, networks that support the active participation of stakeholders from multiple roles and interactions among them could play an important role in educational reforms.

Coordination between individuals with different roles reflects a broad vision of the expertise, from a variety of stakeholders, needed to support systems-level reform. By expertise, we refer to a "broad terrain including problem solving and competencies" (Goldring et al., 2019 p. 198), akin to what Bereiter (2014) described as practical know-how. Expertise, then, is more situated and actionable than just knowledge alone, and concerns what an individual does in their context and is thus different for individuals from different professional roles. This definition of expertise means that what is most important for productive conversations to occur is not that the canonical topics are discussed, but that the conversations are carefully moderated around topics aligned to the focus of the reform effort to provide chances for individuals from different roles to discuss the issues they encounter in their practice.

Balanced participation in terms of the active participation of individuals from different professional roles matters because this has a bearing upon whose expertise, aims, and visions are valued in a network. If, for example, the problems of practice of teachers are not discussedwith conversations solely about researching and evaluating the implementation of the NGSSthen a truly shared understanding of the reform may not be established (Penuel et al., 2011) and trust may not be established among participants (López Turley \& Stevens, 2015). This is also important because some voices - especially teachers - have often been ignored when it comes to reform, to the detriment of the success of the reform itself (Coburn, 2001; Windschitl, 2006). As an example, school administrators need to learn about what science teaching and learning should 
look like in classrooms organized to meet the aims of the NGSS, which requires administrators to learn about ideas for which teachers possess expertise (Lowenhaupt \& McNeill, 2019; Marshall, 2018).

Balanced participation among multiple stakeholders invites key challenges in networks of any kind - social media-based or otherwise - one of which is homophily, the tendency to interact with others who share characteristics, is often found in in-person professional networks in education (Spillane et al., 2012; Spillane et al., 2015). Researchers, for example, may be more likely to choose to converse primarily with other researchers in the course of their work, and teachers with other teachers. This tendency manifests through what is referred to as the process of selection, choosing with whom to connect and interact (Frank, 1998; Spillane et al., 2012; Frank, Muller, \& Mueller, 2013; Wilhelm et al., 2016). Selection can be viewed as the mechanism through which others' resources and expertise are accessed; those who have this access have social capital (Bourdieu, 1980; Portes, 2000). If strong homophily is present in ways that prevent the development of widespread access to others' resources and expertise within a network, then the network may be systematically working better for some rather than others, and it is less likely to support the needed coordination across systems.

Informal, social media-supported professional networks could mitigate individuals' inclination toward homophily (e.g., Lantz-Andersson et al., 2018) because they can involve stakeholders from more roles than are present in many extant professional networks (i.e., those in schools and school districts). Because \#NGSSchat is structured around topics that span from the nature and contents of the Framework for K-12 Science Education to implementing reforms across states adopting standards at different times (Shelton \& Ende, 2015), conversations may be of interest not only to teachers, but also instructional leaders, educational organizations, and others. Moreover, because states adopted and adapted the NGSS at different times, it may also be open to individuals from "lead" states, those presently adopting the standards, and those planning to in the future. Moreover, because of the moderation of \#NGSSchat by a teacher and an administrator, participants who share these professional roles with them may be more likely to identify with and feel welcomed by the moderators. However, we do not know whether their conversations are limited to the moderators and others in the same role, and so it remains important to understand how balanced participation in this professional network may be.

Finally, both the active participation of stakeholders from multiple roles and interactions among stakeholders may be especially important in and relevant to social media-based networks because of how individuals identify with a network or think of a network as being related to oneself or one's work. When identification with an organization or network is low (i.e., when individuals are forced to participate in a group, or otherwise do not perceive themselves to belong in the group), the sharing of ideas and resources from specific, targeted stakeholders with the most expertise can be preferable to shared expertise throughout an organization (Frank et al., 2015; Frank et al., 2018). But, when identification with the group is high, then a message that balances the voices of multiple people - such as one that could emerge from the contributions of individuals from heterogeneous professional roles with different expertise - may lead to success (Frank et al., 2018). As participation in many social media-based networks is voluntary, most participants do so based upon their interest in and identification with the network to a greater extent than in a traditional-possibly mandated-professional learning opportunity. In this way, participation in \#NGSSchat might lead to balanced participation and better coordination between multiple stakeholders working to collectively make sense of the NGSS.

Sustainable Participation Over Time 
The duration of individuals' participation in reform-related activities is a key consideration for any professional network (Garet et al., 2001; Desimone, 2009). However, this may be especially so for social media-based networks because they are not known for fostering individuals' sustained participation. Duration is important for two reasons. First, it provides sufficient time to be involved in the kinds of conversations that can allow individuals to make sense of the NGSS. Particularly given the complexity of implementing a system-wide reform effort (Stiles et al., 2017) and the multiple foundational documents and ideas (i.e., NRC, 2012; National Research NGSS Lead States, 2013) and those related to specific aspects of the NGSS (NRC, 2014, 2015), it is important for participation in such conversations to not be brief or disconnected. Second, the duration of participation matters because it means that individuals can apply what they have discussed in their practice (Coburn, 2001, Desimone, 2009), whether that be as a teacher, administrator, or even a researcher.

Although the accessibility and flexibility of social media-supported professional networks is a benefit, it also relates to the challenge of how sustainable both the networks themselves and participation in them is over time - a key issue and concern on the part of researchers facing their use (Lantz-Andersson et al., 2018; Veletsianos, 2017; Xing \& Gao, 2018). While \#NGSSchat has been active since $2012^{1}$ (Shelton $\&$ Ende, 2015), and so may demonstrate sustainability itself as a network, the extent to which individuals sustain their participation in a voluntary network such as \#NGSSchat - in terms of both how active they are and for how long they remain active - is an important consideration.

The sustained participation of individuals can be affected by many factors, such as having set times (Greenhalgh et al., 2020) and structured conversations (Booth, 2012) and different types of conversations (Greenhalgh et al., 2016; Bucher \& Fiseler, 2017; van Bommel et al, 2020). In light of the different types of conversations that might take place, both transactional and transformational conversations may play an important role; transactional conversations may cultivate a sense of belonging among participants, while transformational conversations may provide value through opportunities to either contribute or receive resources. These might matter because they may affect individuals' later \#NGSSchat activity. Particularly, a process related to the above-referenced selection processes (which can facilitate access to others' resources and expertise) is influence, the process through which access to resources affect individuals' behavior: greater involvement in conversations may relate to sustained participation over time through influence processes. Finally, participation may be different for different individuals. Individuals representing organizations and researchers, for example, might be less likely to sustain their participation than teachers or administrators because of particular, immediate interests. Whereas teachers and administrators might be likely to return to the network year after year. Thus, not only the types of conversations that take place but also the professional role of participants may help to explain who sustained their participation in an informal network such as \#NGSSchat over time.

\section{The Present Study of \#NGSSchat}

To study the characteristics of social media-based professional networks to support science education reform, we make use of a unique dataset, a large collection of tweets from two years of activity on \#NGSSchat (for the 2014-2015 and 2015-2016 academic years), from

\footnotetext{
${ }^{1}$ The \#NGSSchat network remains active at the time of writing this article.
} 
August 1 - July 31 of the following year ${ }^{2}$. A sample of topics obtained from the \#NGSSchat Wikispace website is presented in Table 1; all of the topics are presented in Table S1).

Table 1

Sample of Chat Topics for \#NGSSchat Chats

\begin{tabular}{ll}
$\begin{array}{c}\text { Year of } \\
\text { Chat }\end{array}$ & Topic of Chat \\
\hline 2014 & Chat focused on moving towards integrating and implementing NGSS, starting \\
with the practices. \\
2014 & Chat focused on the practice of engaging in argument from evidence. \\
2014 & Chat focused on the three-dimensional nature of NGSS and what it means for \\
science education. \\
2015 & Chat centered on focusing on phenomena in NGSS. \\
& \\
&
\end{tabular}

Similar to other chats, each \#NGSSchat chat was associated with six questions related to the topic of chat; as Carpenter and Krutka (2014a) explain, in chats that take place via Twitter:

Moderators generally create the slate of questions or prompts for the chat beforehand. At the outset, they collectively welcome participants to the chat and often ask them to introduce themselves. After that, they periodically ask the predetermined questions and interact spontaneously with participants ... supplementary questions, diversions, and side conversations are common too (p. 14).

These questions asked during chats interrogated different aspects of the topic; for example, for a chat on the three-dimensional nature of NGSS and what it means for science education, the six questions aligned with different, particular aspects of the three dimensions of the NGSS (science and engineering practices, disciplinary core ideas, and crosscutting concepts), as in Table 2.

\section{Table 2}

The Six Questions from a Chat from 2014 on the Topic of the Three-Dimensional Nature of the $N G S S$

\footnotetext{
${ }^{2}$ We are confident these chats represent most, but not all, of the chat activity that took place during the two years of activity we studied, as we validated how comprehensive our dataset was through the use of Twitter's Application Programming interface (Borchers et al., 2020). See the archive of all \#NGSSchat chat topics here: https://web.archive.org/web/20170817221156/https://ngsschat.wikispaces.com/.
} 


\begin{tabular}{c} 
Order of Question \\
\hline 1 \\
The 3D nature of \#NGSS is all about making connections. How are you (or \\
how can you) connect the 3 Dimensions? \#NGSSchat \\
\#NGSS connections exist inside each dimension. How does the \\
scaffolded/banded nature of \#NGSS strengthen instruction? \#NGSSchat \\
\#NGSS is connected to \#CCSS in part to help move science from \\
supplement to staple. How do these connections shape your work? \\
\#NGSSchat \\
Learners have to see that branches of science are closely intertwined. How \\
are the CCCs successful (or not) at doing this? \#NGSSchat \\
How does the NGSS make it easier/harder to connect to other content \\
areas? \#NGSSchat (2/2) \\
What steps are you taking (or do you plan to take this year) to help further \\
interweave NGSS into the work that you do? \#NGSSchat
\end{tabular}

In \#NGSSchat (as in others) the moderators played a critical role, but also welcomed others to participate. In this context, we investigated three particular features of \#NGSSchat that stand out for their potential to support science education reform efforts, with an emphasis on how those characteristics may be afforded — and constrained - by the social media context of the network.

\section{RQ \#1: What types of conversations are present?}

The first characteristic we investigated is the depth of the conversations that took placein response to moderators as well as between all participants. To consider the depth and types of conversations, we drew upon van Bommel et al.'s (2020) conceptualization of transactional and transformational conversations as well as sense-making conversations, our addition to van Bommel et al. 's coding frame based upon an open coding process (described in the next section). In addition to conversation type, the alignment of conversations (in terms of both the topics selected for chats as well as the questions moderators posed during them) with the tenets of the NGSS is important, as knowing what types of conversations take place provides more information about the kinds of sense-making that may occur during conversations than coding each contribution to a conversation for its alignment with the NGSS. Accordingly, we examined the alignment of both \#NGSSchat topics as well as the questions asked by moderators to structure each chat (available in Table S2).

RQ \#2: Who, in terms of occupational role and NGSS adoption status, has participated in \#NGSSchat? What explains greater conversations between individuals in different roles?

Second, we investigated who participated in the network. While moderated, \#NGSSchat is also loosely-organized, such that individuals from many professional roles and stages of NGSS adoption may be inclined to join. This feature could provide opportunities for coordination between multiple stakeholders with different kinds and degrees of expertise that are particular to specific roles and professional contexts. Also, we investigated how balanced participation is between individuals; namely, whether individuals from some professional roles participate differently than others, and the extent to which participants are more likely to interact with others in similar roles. Conversations can be considered as a result of selection processes and, therefore, 
the access to and sharing of individuals' expertise. We emphasize that this process, selection, and the process of influence are methodological and theoretical processes that have been shown to undergird how individuals, organizations, and systems change (Carolan, 2014; Frank, 1998; Frank et al., 2018).

\section{RQ \#3: What factors are associated with continued participation over time?}

Third, we investigated the relationship between participation in the network and interactions during the previous year to better understand what leads individuals to sustain their participation year to year. How \#NGSSChat has taken place approximately bi-weekly for nearly eight years and may both reflect, and facilitate, sustained participation, which may provide opportunities for \#NGSSchat participants to make sense of the often complex ideas about the NGSS - and to apply what they are exposed to in their practice (whether as a teacher or administrator or a researcher or a representative of a non-profit organization).

\section{Method}

We used a mixed methods approach involving social network analysis and the use of network models for selection and influence and qualitative coding of conversations, individuals' professional roles, and the alignment of chat topics and questions with the NGSS. Social network analysis is a methodological approach with associated theoretical ideas that are used to understand the nature of social relationships and their effects on outcomes (Carolan, 2014; Wasserman \& Faust, 1994). Educational researchers often carry out social network analysis by asking teachers, administrators, and others about their relationships, such as from whom they seek information or with whom they collaborate (e.g., Spillane et al., 2012). Recently, scholars have begun to look at augmenting and conducting analyses with digital sources of information, including data from the digital traces of interactions within social media platforms (e.g., Greenhow et al. 2019; McFarland et al., 2015), including Twitter (e.g., Rosenberg et al., 2017; Fischer et al., 2019), we qualitatively coded individuals' roles and types of conversations.

\section{Data Sources}

The data from this study comes from all tweets over one academic year archived by the \#NGSSchat moderators on Storify, the platform where the \#NGSSchat network chose to selfarchive all of the tweets associated with the chats ${ }^{3}$. We focused our primary analysis on the 2014-2015 academic year because of the high level of activity this year relative to others. We also chose this year because the 2015-2016 academic year that follows it also exhibited high activity and we needed subsequent years of relatively high activity to understand sustained engagement in the network.

The data set from the chats contained 7,456 original tweets. An original tweet is a single post on the Twitter platform and was, at the time of the study, limited to 140 characters. From these original tweets, we identified conversation threads, or conversations that took place via replies, messages that typically (but not exclusively) began with the screen name of the individual receiving the reply, from one individual to the next. To facilitate the coding, we identified tweets to which any single tweet replied until we identified the longest possible unique thread containing any single tweet. For instance, if Individual 2 replied to a tweet from

\footnotetext{
${ }^{3}$ Tweets were archived by \#NGSSchat organizers on the following website: http://www.ngsspln.com/ngsschat.html. We accessed the data via the Wikispaces website that the \#NGSSchat used to post links to the Storify pages for each chat. We then used the Application Programming Interface from Storify to access the URLs for each of the tweets. Next, we used the rtweet R package (Kearney, 2019) to access additional data on the tweets. Finally, because rtweet (nor the Twitter API) does not provide information about who retweeted or favorited a tweet, we used web-scraping to access this information.
} 
Individual 1, then these two tweets would be considered a part of one thread. In total, we identified 2,468 such threads (with more than one tweet) and 2,739 other tweets (with no replies) which we considered to be unique threads for the purpose of coding, for a total of 5,207 threads, which we refer to simply as conversations for the remainder of this paper.

These conversations that took place through \#NGSSchat were posted by and participated in by 247 unique individuals (or Twitter accounts) that posted more than one original tweet; we reasoned that posting more than one original tweet signified more than superficial use of the hashtag (while still leaving a wide range of degree of involvement). These 247 individuals were active, though some were more so than others: On average, individuals sent 29.83 (median $=10$, $S D=82.01$ ) original tweets. The large standard deviation suggests that while some individuals are involved to a small to moderate degree, some individuals are highly active (see Figure S1).

\section{Measures}

We constructed and used measures for the types of conversations that took place through \#NGSSchat, the alignment of chat topics and questions, characteristics of individuals, and characteristics of interactions between individuals.

Types of conversations. The codes for types of conversations (transactional, sensemaking, transformational, and off-topic; see Table 3) were developed from recent research by van Bommel et al. (2020) for the depth of the conversations that take place through educational, social media-based platforms. In our initial coding of 200 tweets, we noted that our coding frame fell short in one key respect: While it included codes for transactional (exhibiting a simple interaction), transformational (exhibiting a change in knowledge or action), and off-topic (not related to the focus of the group) conversations, these categories did not seem to capture the sense-making (but not transactional, transformational, or off-topic) nature of many of the conversations that we read as a part of our initial coding, or conversations both about the NGSS as well as participants" "ways of understanding" the standards (Rosebery \& Warren, 2008). These conversations involved science education and NGSS-related topics and included questions and answers about the NGSS as well as soliciting resources (such as curricular materials). Thus, we added a sense-making code to van Bommel et al.'s (2020) coding frame and then worked to establish the inter-rater agreement of this expanded coding frame by independently coding the same 100 tweets that were a part of conversations, after which we achieved strong inter-rater agreement (94\% [Cohen's $\mathrm{K}=.87])$. Conversations were coded with only one code.

\section{Table 3}

The Coding Frame for the Type of Conversation

\begin{tabular}{cll}
\hline Code & \multicolumn{1}{c}{ Code Description } & \multicolumn{1}{c}{ Example } \\
\hline $\begin{array}{l}\text { Transactional } \\
\text { Conversation }\end{array}$ & $\begin{array}{l}\text { Affirmations of what was shared } \\
\text { introductions; simple posts with content; } \\
\text { inviting others to chats or specific } \\
\text { conversations; restating in different words } \\
\text { or adding a new name for the same thing } \\
\text { that was said; may be single tweets (rather } \\
\text { than two or more tweets in a conversation). }\end{array}$ & $\begin{array}{l}\text { Participant 1: Need a good } \\
\text { data set for students and not } \\
\text { sure where to get it? Try }\end{array}$ \\
& $\begin{array}{l}\text { \#ngschat } \\
\text { farticipant 2: Thank you } \\
\text { for your support! Lots of } \\
\text { additional materials for }\end{array}$
\end{tabular}




\begin{tabular}{|c|c|c|}
\hline & & $\begin{array}{l}\text { science teachers coming } \\
\text { soon! }\end{array}$ \\
\hline $\begin{array}{l}\text { Sense-Making } \\
\text { Conversation }\end{array}$ & $\begin{array}{l}\text { Discussions of NGSS- and science } \\
\text { education-related content; asking elicitation } \\
\text { questions, sharing additional resources, } \\
\text { and/or building upon this sharing of } \\
\text { resources/content; must include two or } \\
\text { more tweets to be considered as this code. }\end{array}$ & $\begin{array}{l}\text { Participant 1: Sorry to be } \\
\text { negative, but easier to say } \\
\text { what to avoid. No canned, } \\
\text { hokey 'engineering' } \\
\text { activities not connected to } \\
\text { bigger ideas. } \\
\text { Participant 2: @Participant } \\
\text { 1: agreed. Too often } \\
\text { engineering projects are } \\
\text { activity mania. Need to be } \\
\text { grounded in science } \\
\text { concepts. \#NGSSchat }\end{array}$ \\
\hline $\begin{array}{l}\text { Transformational } \\
\text { Conversation }\end{array}$ & $\begin{array}{l}\text { Reflections or exhibitions of an individual's } \\
\text { change in knowledge or practice including } \\
\text { reporting changes in practice; must include } \\
\text { two or more tweets to be considered as this } \\
\text { code. }\end{array}$ & $\begin{array}{l}\text { Participant 1: School-based } \\
\text { teams and K-12 NGSS } \\
\text { exploration teams have } \\
\text { been really great in our } \\
\text { state to explore } \\
\text { progressions \#NGSSchat } \\
\text { Participant 2: } \\
\text { @ Participant1 I'd love to } \\
\text { learn more about that. What } \\
\text { / who would be the best } \\
\text { way to do that? \#NGSSchat } \\
\text { Participant 1: @Participant } \\
2 \text { I've been leading a couple } \\
\text { groups here...email me } \\
\text { whenever you like <email } \\
\text { address redacted }> \\
\text { \#NGSSchat }\end{array}$ \\
\hline $\begin{array}{c}\text { Off-topic } \\
\text { Conversation }\end{array}$ & $\begin{array}{l}\text { Not NGSS- or science education-related; } \\
\text { including conversations about the } \\
\text { mechanics of using Twitter and inside jokes } \\
\text { between individuals; and for conversations } \\
\text { that are not transactional, sense-making, or } \\
\text { transformational }\end{array}$ & $\begin{array}{l}\text { Participant 1: Coherence is } \\
\text { so important. How do we } \\
\text { express with one voice and } \\
\text { one direction? \#NGSSchat } \\
\text { Participant 2: @Participant } \\
1 \text { I hear \#onedirection is } \\
\text { looking for a new voice. } \\
\text { Can@Participant } 3 \text { carry a } \\
\text { tune? }\end{array}$ \\
\hline
\end{tabular}

Alignment of chat topics and questions. To check the alignment of not only the chat topics (Table S1) but also the six questions asked by moderators during them (Table S2), we 
coded topics and questions (separately) by considering whether each question moderated during a chat was related back to the NGSS or its implementation. Two coders independently coded each question as (1) being aligned to NGSS or (0) not being aligned to NGSS. Interrater reliability for coding chat topics was $100 \%$ and interrater reliability for chat topics was $94.8 \%$; all disagreements for chat topics were able to be resolved through discussion. We found that all of the topics and questions were aligned with the tenets and practices of the NGSS.

Professional role. To determine the participants' professional role, we first open-coded (see Miles et al., 2014) profiles to develop a coding frame (see Table S3). We then applied this coding frame to the data independently. Each user's self-authored Twitter profile was independently coded by the first two authors for one of five codes for their professional role: teacher, administrator, researcher, organization, and others ${ }^{4}$. Inter-rater reliability was established by two rounds of coding, each round consisting of a random sample of 20 participants until agreement of $70 \%$ (with all disagreements resolved through discussion) was achieved.

NGSS adoption status. We used the geographical location of each individual in the networks to assign the adoption status of each individual's state as a variable to each individual with this data available. To identify the location of participants, we access the location field from each individual's profile, which has been shown to lead to accurate or approximate results for around $80 \%$ of Twitter participants (Greenhalgh et al., 2018). We then used the Google Maps API to geocode the participants' location. We were able to identify $78 \%(n=193)$ of users' locations, with $65 \%(n=168)$ able to be assigned to one of the fifty U.S. states. The difference in percentages is due to being unable to assign some locations to states (i.e., for individuals whose locations were found to be outside of the United States or in the United States at the countrylevel). Next, we assigned each state to one of four levels of a variable for when the state adopted the NGSS (Early NGSS, Late NGSS, Early NGSS-aligned, Late NGSS-aligned, and location missing, or N/A). We considered early NGSS adoption to be the adoption of the NGSS before the 2014-2015 school year, and late NGSS adoption to be their adoption after the 2014-2015 school year but before the 2019-2020 school year. We considered Early NGSS-aligned and Late NGSS-aligned to be the adoption of NGSS-aligned standards (but not the official NGSS) for those same periods. Because of the uncertainty inherent to geocoding (Greenhalgh et al., 2018), we used this measure only in a descriptive manner and to understand the distribution of participants' locations, rather than as independent variables in analyses.

Number of conversations between individuals. To determine how extensive conversations were between individuals, we calculated the number of conversations of each type in which each unique pair of participants were involved. For example, if two participants were involved in three transactional conversations involving the other, then the value for this measure for each of these participants would be three.

Same professional role. To determine how the extent to which homophily is evidenced through interactions, for every unique pair of participants, we determined whether or not they shared a professional role, and then used this measure in analyses involving interactions between individuals.

Involvement in conversations with central \#NGSSchat participants. To determine the effect of involvement in conversations, we calculated the number of interactions (calculated separately for each of types of conversations) a participant received weighted by the in-degree centrality of the interaction sender during the year of the study. This allows us to account for the

\footnotetext{
${ }^{4}$ Although those in the other role were not coded as belonging to one of the other four roles, they were still, in general, stakeholders in the NGSS, such as parents or those involved in education, but in an unclear capacity.
} 
role of participation in conversations with more-and more central, and therefore potentially more influential - participants in the network.

Sustained participation. To determine sustained participation, we calculated the number of tweets an individual sent after the year of the study (August 1, 2015-July 31, 2016).

Data Analysis

Preliminary analyses. To begin to understand the data and to prepare it for subsequent analyses, the conversations were processed into a key social network analysis data type, an edge list. We used the statistical software R (R Core Team, 2020) for these preliminary analyses and subsequent analyses. We then generated a sociogram, or a network visualization, based on the edgelist to visualize the conversation network using the ggraph $\mathrm{R}$ package (Pederson, 2018). We also used the edgelists for the analyses for RQ \#3.

Analysis for RQ \#1: What conversations take place through \#NGSSchat? This analysis involved manually coding the conversations that took place through \#NGSSchat. To present these results, we summarized the coding quantitatively (through calculating the proportion of tweets that were coded with one of the four codes) and qualitatively (through selecting examples of conversation coded with each of these codes). To describe the frequency of the conversations, we calculated the number of each type of conversation and their proportion of all conversations, and the mean number of tweets present, and professional roles represented within each type of conversation, and the proportion of individuals by professional role participating in one or more of each type of conversation. We note that in the qualitative results, profiles were blinded for publication. We replaced profile names with their role and a number that indicated whether each role was the same individual profile or different for reasons described in the discussion.

Analysis for RQ \#2: Who has participated in \#NGSSchat and what explains greater conversations between individuals? First, for an individual's professional roles, we calculated the number (and proportion) of the \#NGSSchat participants for each professional role. We also calculated the mean in-degree centrality for individuals from each role for each conversation type. For NGSS adoption status, we described the number (and proportion) for each and created a map to depict where \#NGSSchat participants were from.

We also intended to explain the number of conversations between individuals. While many similar social network analysis models predict the presence or absence of interaction (Zijlstra et al., 2006), other models predict the number of conversations between individuals (e.g., Frank, 2009), which are especially common in social media data. The particular selection model that we used was a multi-level $P 2$ model (Zijlstra et al, 2006), a cross-classified multilevel model (Raudenbush \& Bryk, 2002) with a count dependent variable. These models are intended to explain the number of times two \#NGSSchat participants interacted through a Poisson dependent variable distribution while accounting for senders' (or receivers') tendency to send (or receive) replies as a part of conversations. The coefficients are Incident Rate Ratio (Gelman \& Hill, 2006), which is similar to an odds ratio; both result from exponentiating the raw coefficients output from the model, which are natural log-odds units $\left(\log _{e}\right)$. To specify the models, we used the brms R package (Burkner, 2017). ${ }^{5}$ The independent variables used for sending or receiving replies as a part of each of the four types of conversations included which

\footnotetext{
${ }^{5}$ Particularly for complex multi-level models (such as $p 2$ models), typical estimation approaches can be challenging to use. The brms package uses MCMC estimation, which can aid in the estimation of such models. Another advantage of the use of MCMC is that with typical GLMs, there is a violation of the assumption that the variance and mean of the outcome are equal: MCMC accommodates the uncertainty due to this. We followed Kruschke's (2015) guidelines for checking the representativeness, accuracy, and efficiency of the estimation process.
} 
professional role the individual was a member of, separately for senders and receivers of each type of conversation. The other role served as the reference group; we also conducted post hoc for group-wise differences. Last, we added a homogeneity variable for whether individuals were from the same professional role. We interpreted the coefficients and average marginal effects (AMEs; which represent the effect not in terms of the Incident Rate Ratio, but in terms of the scale of the dependent variable) as well as their standard errors (and $p$-values) to determine the magnitude, direction, and statistical significance of the effects.

\section{Analysis for RQ \#3: What factors are associated with sustained participation?}

For this analysis, we sought to understand how sustained participation might be a product of who conversed with one's tweets during the 2014-2015 academic year that is the focus of this study. A GLM model was used to predict sustained participation measured as the number of original tweets each individual sent to \#NGSSchat in the 2015-2016 academic year. Independent variables included each individual's professional role (with, like for the analysis for RQ \#3, the other role serving as the reference group, with post hoc tests for group-wise differences) and a term representing involvement in each of the types of conversations. Because the dependent variable represents a count (or rate), we again specified a Poisson dependent variable distribution. The term for involvement in conversations was intended to capture not only how many conversations (considered separately for each of the conversation types) an individual participated in, but, how conversations may matter more when sent by influential individuals. Accordingly, these terms involved determining the number of times every other individual interacted with each individual and then multiplying that number by a centrality measure (indegree centrality). Thus, these terms were intended to account for participating in conversations in which one received replies from central individuals, who may have a greater influence on others' sustained participation. Finally, these multiplied terms were summed to create a total value for conversations for each individual. Like in the analysis for RQ \#2, we interpreted the Incident Rate Ratios as well as their Average Marginal Effects, as well as their standard errors (and $p$-values) to determine the magnitude, direction, and statistical significance of the effects.

\section{Results}

\section{Preliminary Analyses}

In this analysis, we aimed to visually explore between whom conversations that took place through \#NGSSchat involved. The network visualizations for conversations we created are presented in Figure 1. Wider edges, or lines, depict a greater number of particular types of conversations between individuals; larger nodes, circles, depict individuals with a greater centrality in the network. From these, we can see that transactional conversations are characterized by a dense structure, wherein many individuals receive replies from central individuals, particularly, an administrator who received very many replies as a part of transactional conversations (see the triangle near the center of the figure) and teacher (circle). Sense-making conversations were also dense but appeared to evidence greater conversations between individuals other than those who were highly central to the network, as shown by more connections among different nodes. Transformative and off-topic conversations were both much less dense, particularly for transformative conversations, which appeared to take place between a few individuals; in addition to being less dense, off-topic conversations were very infrequent (and so were not included in Figure 1). The visualizations also show preliminary evidence that participation in the different conversation types includes individuals from different roles (i.e., shows heterogeneity), and that most of the roles appear to be both sending and receiving replies. Figure 1 
Network Visualizations for Each Type of Conversation (Transactional, Sense-making, and Transformational)

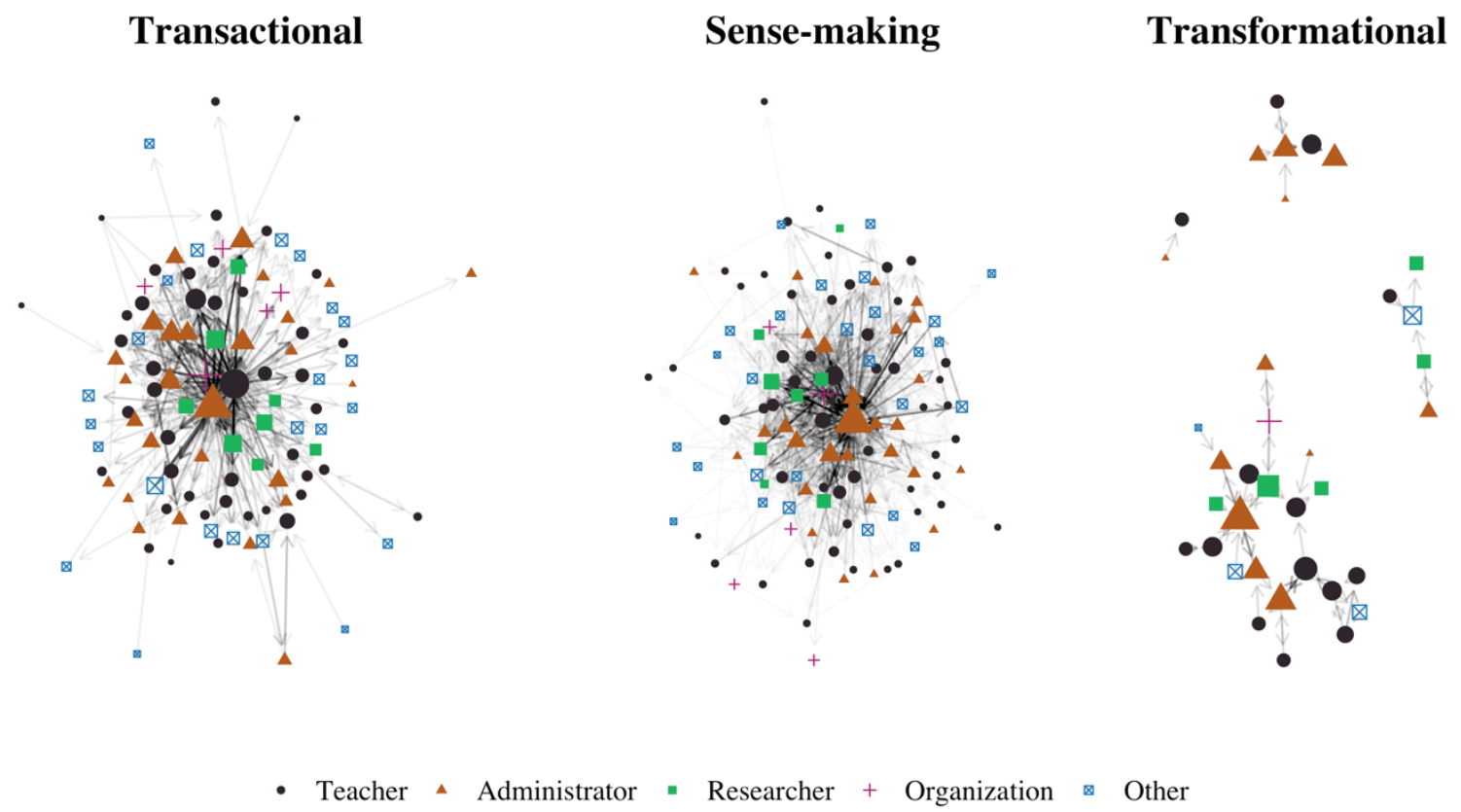

Notes. The width of the edges, or lines, depict the number of interactions between participants. The size of the nodes, or shapes, depict the in-degree centrality of the participants. To facilitate interpretation, only the individuals who posted 10 or more original tweets to \#NGSSchat during the year of the study. Off-topic conversations were very infrequent and so were not included in this. In subsequent analyses, off-topic conversations were not used, and substantive and transformative and conversations were combined; see the Results for RQ\#1 for a description of why.

\section{Results for RQ \#1: The Types of Conversations That Take Place Through \#NGSSchat}

The coding resulted in descriptive statistics about the conversation types. Regarding the relative frequency of the different conversations, transactional $(n=3,584 ; 68.8 \%$ of all conversations), and sense-making $(1,597 ; 30.6 \%)$ conversations were the most common; these collectively comprised a large proportion of all of the conversations. A much smaller proportion $(n=17 ; 0.3 \%)$ of conversations were transformative ${ }^{6}$, with a smaller number still off-topic (8; $0.1 \%$ ), which, while described here, were not included in subsequent analyses.

For conversations with more than a single tweet (i.e., holding aside the conversations coded as transactional that were single tweets without replies), sense-making conversations were the most common ( $64.7 \%$ of conversations with more than one tweet), followed by transactional $(34.2 \%)$ and then transformational $(0.7 \%)$ conversations. As we discuss later, we think that these sense-making conversations - characterized by the discussion of NGSS- and science educationrelated content - are important because they allow participants to make sense of the NGSS and their and others' roles in implementing the NGSS. We note that while transactional interactions are both frequent and more social in nature than those that are sense-making (or transformative),

\footnotetext{
${ }^{6}$ We chose to combine conversations coded as transformative with those coded as sense-making for the conceptual and practical reasons we describe in the results for RQ \#3.
} 
they may have an important role to play, especially regarding individuals' sustained participation in the network over time.

The coding also provided a context for us to select representative examples.

Transactional conversations were frequently brief affirmations of answers or posts, as in the following conversation:

Teacher 1: Thanks@Administrator $1 @$ Administrator 2 for all that you do! \#NGSSchat Administrator 1: @Teacher 1@Administrator 1 It's amazing to learn with my \#NGSSchat PLN! Going to Chicago?

While many transactional conversations referenced science education content, the conversations were more social than sense-making in nature:

Researcher 1: A3: Drawing on @Researcher 2's work, we organize sequences into cascades of practices anchored to phenomena: http://t.co/u3QIcI8J1C \#NGSSchat Researcher 2 reply to Researcher 1: @Researcher 1 Thanks for the online fist bump! \#NGSSchat

Other conversations were primarily social but were still related to NGSS-related activities

Administrator 1: Amazing to think that first "met" @Administrator 2 on Twitter over 2 years ago, now co-coordinators of NGSS@NSTA curation work! \#ngsschat

Administrator 2 reply to Administrator 1: @Administrator 1 We've come a long way in 3 years :) \#NGSSchat

Administrator 1 reply to Administrator 2: @Administrator 2 Three years?! Have I already lost count?! \#ngsschat

Last, some transactional conversations were not replied to, or were unreciprocated, as with the following:

Administrator 1: Personally, I love @Other 1's "designing easy inquiries" as a way to develop mental models: http://t.co/N3wt8GSuTx \#ngsschat

Sense-making conversations - as noted above - demonstrated involvement with one another's ideas or the science education content, as in the following, which emphasized the importance of the cross-cutting concepts, one of the three dimensions of the NGSS (NGSS Lead States):

Administrator 1: I'm really going to work on the CCC ideas! How to help people embrace and use them. \#NGSSchat

Researcher 1 reply to Administrator 1: @Administrator 1 Awesome. If you get exciting projects going, please try to loop in researchers. We need to study the CCCs! \#NGSSchat These sense-making conversations also evidence engagement with broader ideas related to implementing policies related to the NGSS:

Organization 1: A4: Doing great work in WI on standards-based report cards for \#science, but still need more work on it \#ngsschat

Administrator 1 reply to Organization 1:@Organization 1 Would love to take a look at where you're going with that if you can share.

Organization 1 reply to Administrator 1: @Administrator 1 I'll share widely and post on \#ngsschat as we get something formal put together

Administrator 2 reply to Organization 1:@Organization $1 @$ Administrator 2 This is awesome, I look forward to seeing what you put together. \#NGSSchat Transformative conversations - different from those which were considered to be sensemaking - demonstrated some type of change in one's knowledge, as in the following discussion of how an administrator, in response to an answer to a question posted by an organization, was coming to recognize the importance of technology-based networks for implementing the NGSS: 
Organization 1: A1: Capacity for \#ngss implementation will only be reached with the creation of/use of networks and taking advantage of technology. \#NGSSchat Administrator 1 reply to Organization 1: @Organization 1 I agree with the necessity for maximizing tech, but can you clarify what kind of networks you mean? \#ngsschat Organization 1 reply to Administrator 1: @Administrator 1 I mean that we can not succeed if we work individually. We must collaborate in existing \& new pers./prof. networks. \#NGSSchat

Administrator 1 reply to Organization 1: @Organization 1 I was guessing that was what you meant - the more I get into this, the more I see how much a support network is critical \#ngsschat

Other transformative conversations concerned individuals' statements about intending to change one's practice by accessing a new resource, as in the following conversation between two teachers and three administrators about the rigor of NGSS-aligned chemistry courses, and the interest of teachers to access materials related to a new course an administrator was developing:

Administrator 1: Some teachers I know are willing to change their instruction for "regular" chem, but not "honors" chem...thoughts? \#NGSSchat

Teacher 1 reply to Administrator 1: @,Administrator 1 this goes back to the fear that \#NGSS isn't rigorous enough 4 college readiness. Many still think coverage $=$ rigor \#NGSSchat

Administrator 2 reply to Teacher 1: @Teacher 1@Administrator 1 Happy to share a chem course I've been working on. Shows depth. \#NGSSchat

Administrator 3 reply to Administrator 2: @Administrator $2 @$ Teacher 1

@Administrator 1 Something like that would answer chem Ts questions. NGSS leaves some feeling marginalized \#NGSSchat

Administrator 2 reply to Administrator 3: @Administrator $3 @$ Teacher 1

@Administrator 1 Working now on a set of YouTube type Vs to explain bonding, gas laws, and inst. seq. \#NGSSchat

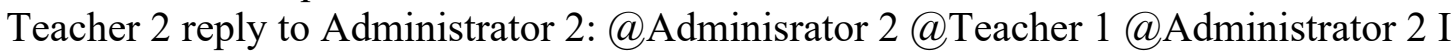
would love to see this! \#NGSSchat

Administrator 2 reply to Teacher 2: @Teacher $2 @$ Teacher $1 @$ Administrator 2 Email me. \#NGSSchat

Last, off-topic conversations were the most infrequent but consisted of conversations not related to the \#NGSSchat or NGSS content. For instance, the following conversation is not related to the chat nor NGSS content:

Administrator 1: I'm always amazed how quickly@Administrator 2 and @Administrator 3 can type in welcome response tweets \#NGSSchat

Administrator 3 Reply to Individual 1: @Administrator $1 @$ Administrator 2 We have clones. \#NGSSchat

Finally, as Table 4 demonstrates, while a small proportion of conversations were transformative, they, followed by those coded as sense-making, were longer and involved more participants and more participants from distinct professional roles. Concomitantly, we also found that most participants were involved in one or more transactional $(175 ; 71.9 \%)$; and sensemaking (205; 83.0\%) conversations, while fewer (though still a substantial proportion) participated in transformative $(36 ; 14.6 \%)$ conversations.

\section{Table 4}


Descriptive Statistics for the Different Types of Conversations

\begin{tabular}{cccc}
\hline Measure & $\begin{array}{c}\text { Transactional } \\
\text { Conversation } M(S D)\end{array}$ & $\begin{array}{c}\text { Sense-making } \\
\text { Conversation } M(S D)\end{array}$ & $\begin{array}{c}\text { Transformative } \\
\text { Conversation } M(S D)\end{array}$ \\
\hline $\begin{array}{c}M \text { length }(S D) \\
\quad \text { individuals }\end{array}$ & $2.22(.925)$ & $3.27(2.41)$ & $5.29(2.78)$ \\
$\begin{array}{c}\text { participated in at } \\
\text { least one }(\%)\end{array}$ & $205(70.85 \%)$ & $205(82.99 \%)$ & $36(14.57 \%)$ \\
$\begin{array}{c}M \text { individuals } \\
\text { participated }(S D)\end{array}$ & $1.96(0.53)$ & $2.33(1.11)$ & $3.24(.97)$ \\
$\begin{array}{c}M \text { professional roles } \\
\text { participated }(S D)\end{array}$ & $1.65(.56)$ & $1.82(.77)$ & $2.18(.52)$ \\
\hline
\end{tabular}

Note. Off-topic conversations were not included on the basis of their infrequency $(n=7,0.01 \%$ of all conversations).

Collectively, these results point to how sense-making and transactional conversations exhibit greater involvement from individuals, while transformative conversations - though common-were less frequent than those types. Transformative and off-topic conversations were found to be very rare, yet, still, more than $10 \%$ of individuals were involved in at least one transformative conversation.

\section{Results for RQ \#2: \#NGSSchat Participants' Role and NGSS Adoption Status}

The analysis for professional roles coding revealed teachers as the plurality within the network $(37.90 \% ; n=94)$ followed by those in the other professional role $(28.62 \% ; n=71)$, administrators $(21.3 \% ; n=53)$, researchers $(6.9 \% ; n=17)$, and organizations $(5 . \% ; n=13)$. This variation shows that although teachers are the largest group of individuals using \#NGSSchat, substantial heterogeneity in their roles was evidenced.

The analysis of NGSS adoption status showed that $47.6 \%$ of individuals $(n=80)$ were from states which adopted the NGSS (or NGSS-like standards) early (before the 2015-2016 academic year); $40.4 \%(n=68)$ from those who adopted the standards late (during and after the 2015-2016 academic year); and $11.9 \%(n=20)$ were from states that did not adopt the NGSS. Figure 2 illustrates these differences and suggests that individuals participating in \#NGSSchat did so from across the US, without clear geographical clustering.

\section{Figure 2}




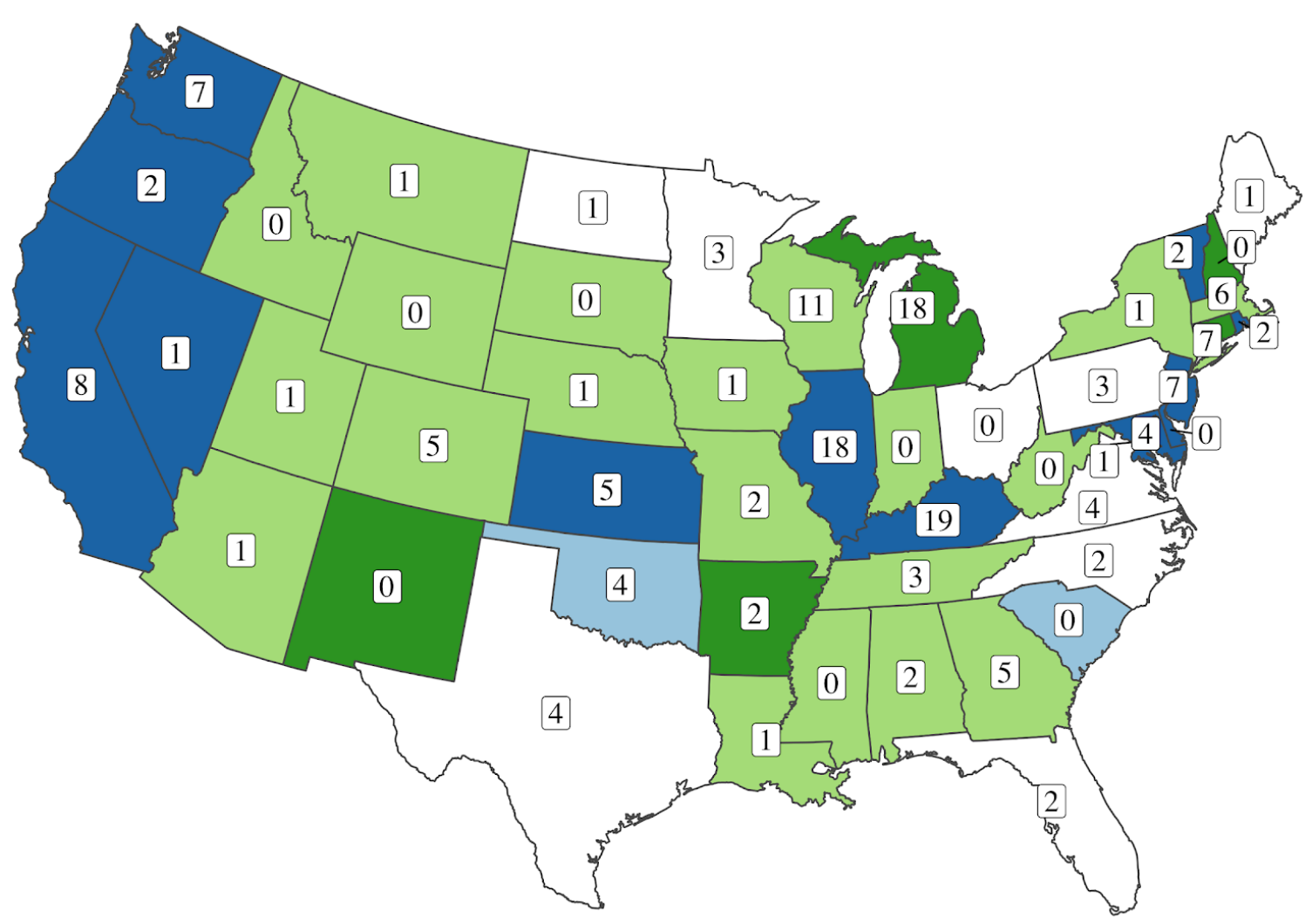

Note. Early NGSS denotes a state's adoption of the NGSS before the 2014-2015 school year and Late NGSS denotes a state's adoption of the NGSS after the 2014-2015 school year but before the 2019-2020 school year. Early-NGSS-aligned and Late NGSS-aligned denote the adoption of NGSS-aligned standards (but not the official NGSS) for the same periods. No individuals were from Alaska, Hawaii, or other United States territories, and two individuals were from locations outside of the United States. N/A indicates that the state had note adopted the NGSS or NGSSaligned standards before the 2019-2020 school year.

\section{Results for RQ \#2: Conversations Between \#NGSSchat Participants}

This analysis provides insight into who initiated (or sent) and who received replies based on their professional role. Overall, we found that individuals in different professional roles sent and received replies at different rates, and individuals had a slight tendency to interact more with others in the same professional role.

Because of the relatively small number of transformative conversations, we carried out analyses for who sent and received replies as a part of transformative conversations combined with sense-making conversations, and with transformative conversations independent of this other type of conversation. Because none of the coefficients were found to reach the criterion for statistical significance in the analyses with only transformative conversations - and the direction, magnitude, and statistical significance of the effects for sense-making did not change when the transformative conversations were included with sense-making conversations - we 
chose to combine these types of conversations in these analyses, and to refer to this combined value as sense-making conversations for brevity. Table 5 presents the results.

\section{Table 5}

Selection Models for Sending and Receiving Replies Through Conversations

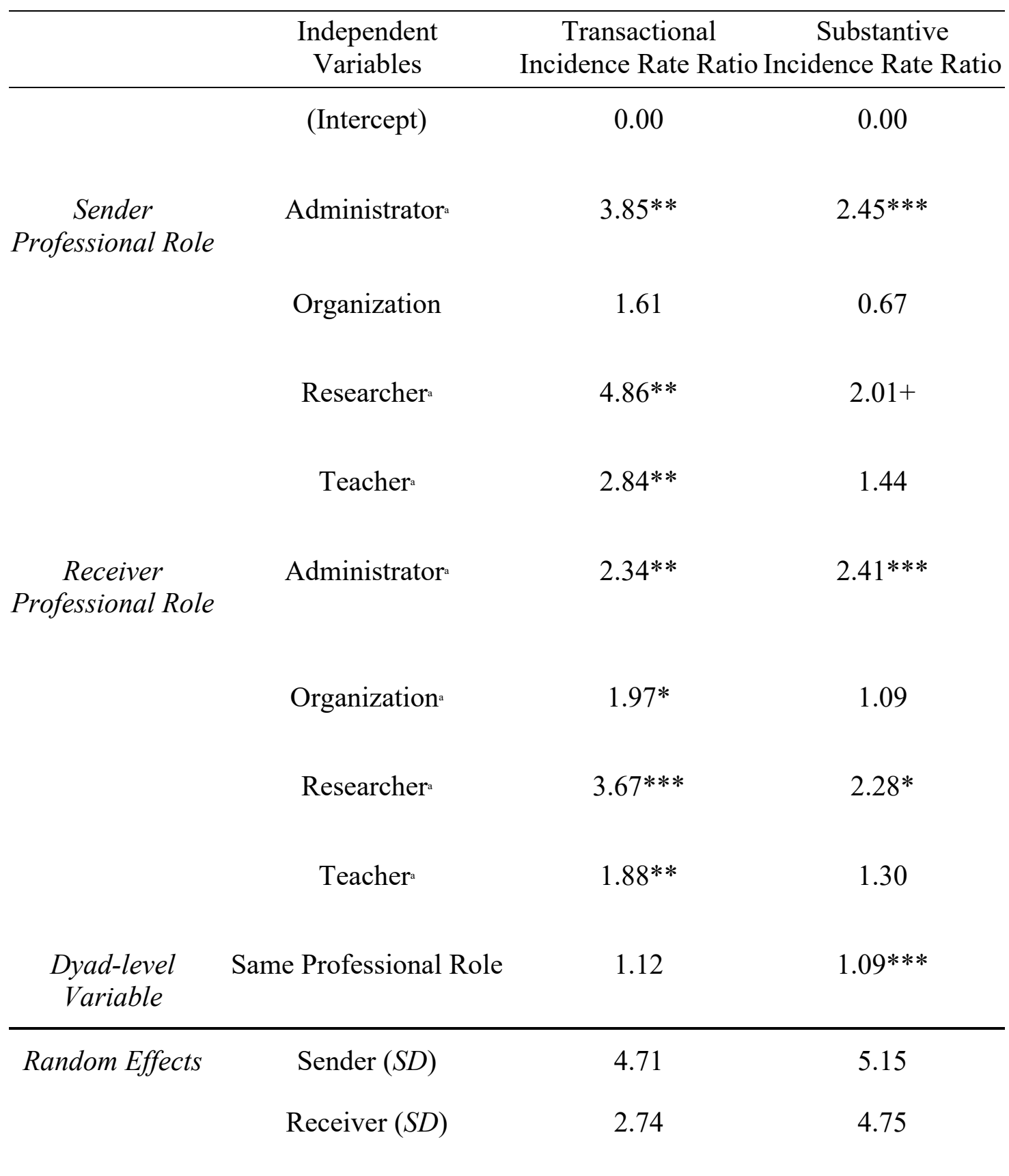

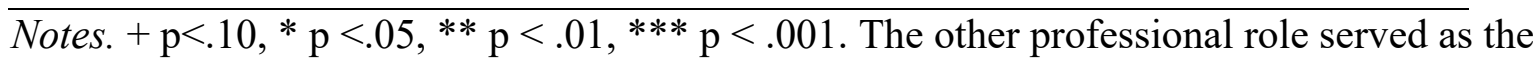
reference group for the other roles. Superscripts indicate groups with effects that were found to not be different based on post-hoc tests (see Table S3). Substantive conversations represent the combined number of sense-making and transformative conversations. 
Conversations were sent to different extents depending on the individual's professional role. To interpret this table, consider an individual who is a researcher and is otherwise similar to other individuals. Values greater than one indicate that an additional conversation is sent or received is more likely; values less than one indicate that an additional conversation is less likely. The coefficient associated with the association of being a researcher on sending transactional replies is positive and statistically significant. Because the Incident Rate Ratio value of 4.86 is interpreted as a rate, it can be interpreted as increasing the count of conversations sent by researchers at this rate (accounting for the effects of other variables). Also, we note that while the reference group is the "Other" professional role, this comparison is less helpful than the pairwise comparisons between groups, which show how the effect of belonging to any one professional role differs from the others (Table S5).

Conversation replies were sent to a different extent depending on the individual's professional role. Administrators stood out for their high rate of sending, or initiating, replies as a part of both transactional and substantive conversations to a greater extent than those in the other role. While researchers were even more likely to send transactional conversations than administrators, individuals from both these professional roles as well as teachers were not found to be different from one another in terms of their rate of sending replies, with organizations being associated with slightly lower participation (Table S5); the observed differences were with those in the other role which served as the reference group.

Replies were also received to different extents depending on the individual's role. Researchers and administrators stood out for their high rate of receiving replies in both transactional and substantive conversations, while teachers received more transactional - but not substantive-replies than those in the other role. As for sending replies, there were not any statistically significant differences between these roles (Table S5). These findings suggest that one professional role is not privileged over others when it comes to participating in conversations, as long as participants' role is either as a teacher, administrator, researcher, or an organization, with implications for how \#NGSSchat may provide access to expertise to those participating in it, as we later discuss.

Finally, we found that individuals demonstrated a small tendency to converse with others with whom they shared the same professional role, though this tendency was small relative to the effects of professional roles and the sender and receiver random effects: Individuals who share a professional role were $9 \%$ more likely to have an additional conversation. Transactional conversations did not exhibit this homophily tendency: Conversations were found to be equally likely between individuals from different professional roles as those between individuals from the same professional role. Transactional conversations may reflect a more accessible type of interaction for those from different professional roles than substantive conversations, and individuals may converse more substantively because they share more similar concerns, questions, or interests.

We note that these rates are relative to the intercept, which has a very small magnitude. The Incident Rate Ratio of 4.86 for the effect of a researcher sending a reply as a part of a transactional conversation is multiplied by the Incident Rate Ratio for the intercept to yield a rate of 0.003 , less than a one in 100 predicted chance of a researcher sending a reply to any other individual. If the receiver is also a researcher (Incident Rate Ratio: 3.67), then the rate increases to 0.013 . In other words, for any two researchers in the network, their rate of conversing transactionally is 0.013 , or a $1.13 \%$ chance. Thus, these effects are small in magnitude. In this context, we also note the random effects in the output. In the output, these present the standard 
deviation of the individual sender and receiver random effects, which model the effects specific to each \#NGSSchat participant. Their standard deviation is large in magnitude: 4.71 for senders and 2.74 for receivers. The inspection of the estimates for the random effects shows that a few individuals seem to have a very large effect: Simply being one of these individuals increases the rate of sending replies to any other individual by those amounts, leading to predicted differences in the rates of sending replies as a part of transactional conversations, for examples, for the individuals with the largest estimates by as much as 0.15 . Thus, what this model showsoverall — is that while professional roles do matter (and are associated with statistically significant differences in the rate of sending and receiving replies), the differences appear to be driven by a relatively small number of highly influential individuals.

\section{Results for RQ \#3: Factors Associated with Sustained Participation}

This analysis provides insight into what sustains the participation of \#NGSSchat participants over time, which we operationalized as the number of original tweets sent in the year following the study, regardless of the types of conversations in which individuals participated. Like for RQ \#3, we combined sense-making and transformational conversations, and refer to this combined value as substantive conversations for brevity. The coefficients in Table 6 are interpreted as an Incident Rate Ratio, because the dependent variable is a count variable, like for RQ \#2. For example, the coefficient associated with being an administrator is associated with an Incident Rate Ratio of 1.55, indicating that administrators are 55\% more likely to send an additional original tweet in the year following the study than in the other role (see the measures). As for the previous results, we direct attention to the pairwise comparisons from post hoc tests (see Table S6), which show how the effect of belonging to any one professional group differs from that for belonging to the others.

Table 6

Results for Influence Models Predicting Sustained Participation in \#NGSSchat

\begin{tabular}{ccc}
\hline Independent Variables & $\begin{array}{c}\text { Incidence } \\
\text { Rate Ratio }\end{array}$ & $\begin{array}{c}\text { Average } \\
\text { Marginal Effect }\end{array}$ \\
\hline Intercept) & 8.34 & 2.12 \\
Involvement in Transactional Conversations & $1.83^{* * *}$ & $14.85^{* * *}$ \\
Involvement in Substantive Conversations & $1.45^{* * *}$ & $9.01^{* * *}$ \\
Administrator & & $16.80^{* * *}$ \\
Organization $^{\mathrm{b}}$ & $1.79^{* * *}$ & \\
Researcher $^{\mathrm{c}}$ & $0.20^{* * *}$ & $-16.91^{* * *}$ \\
& & $-7.19^{* * *}$
\end{tabular}


Teacher $^{\mathrm{d}} \quad 1.90 * * * \quad 19.06^{* * *}$

Notes. $+\mathrm{p}<.10, * \mathrm{p}<.05, * * \mathrm{p}<.01, * * * \mathrm{p}<.001$. The other professional role served as the reference group for the other roles. Superscripts indicate groups with effects that were found to not be different based on post-hoc tests (see Table S4). Substantive conversations represent the combined number of sense-making and transformative conversations.

We found notable differences in sustained participation based on the professional role to which each individual belonged. In particular, the effects associated with professional roles were also statistically significantly different from one another except for that between administrators and teachers (Table S6). For these analyses, the Average Marginal Effect represents the effect of a one-unit change in the independent variable in terms of the number of original tweets in the year following the study. For example, a one-standard-deviation increase (because these variables were standardized) in involvement in transactional conversations was on average, associated with 14.85 more tweets the following year. Teachers, especially, stood out as being more likely to participate in the year following the study, being more likely than those in the other role (with an Average Marginal Effect of 19.06 relative to those in the other role ${ }^{7}$ ) to post additional tweets in the year following the year of the study, and, according to post hoc tests, were more likely than any of the other three roles to post an additional tweet ${ }^{8}$. Administrators, too, were likely to sustain their participation (relative to those in the other role [AME: 16.80], as well as researchers $[A M E: 24.00]$ and organizations [AME: 33.71]). Researchers (AME: -7.197) —and especially organizations $(A M E:-16.99)$ —were found to be less likely to continue to be involved in \#NGSSchat in the following year compared to teachers, administrators, and researchers. In short, the two groups who are most likely to work in schools - teachers and administrators - were found to be more likely to exhibit sustained participation.

Finally, and importantly, we found differences based upon involvement in transactional and substantive conversations or the number of such conversations in which individuals participated. We note that this involvement captures not only how many conversations an individual was exposed to, but also who was participating in them (based on the centrality of the individual sending the reply as a part of a conversation). Thus, involvement was calculated in a way that was intended to capture the total effect of receiving replies - and, potentially, expertise - over time. We focus on the AMEs to help us to understand the difference in sustained participation on the scale of the dependent variable. The effect of involvement in conversations can be interpreted in terms of a one-standard-deviation increase in the independent variable: individuals posted 14.85 additional tweets in the year following the year of the study for a oneunit increase in such involvement in transactional conversations, and 9.01 additional tweets for every one-unit increase in involvement in transactional conversations. Therefore, not only one's professional role, but also how one participates in the network matters, with involvement in transactional and substantive conversations both relating to sustained participation, but with a stronger effect for involvement in transactional conversations.

\section{Discussion}

\footnotetext{
${ }^{7}$ The Average Marginal Effect for individuals in the other group, which accounts for involvement in transactional and transformational conversations, was 0.11 ). 8
} 
We sought to understand how the social media-based professional network \#NGSSchat connected diverse stakeholders that are integral to implementing NGSS reforms and allowed for substantive interactions. Overall, we found 1) transactional, sense-making, and transformative, conversations took place through \#NGSSchat; 2) participation among teachers, administrators, and researchers sent and received replies in conversations at similar rates; and, 3) receiving greater transactional and substantive (which included both sense-making and transformational) conversation replies from central participants in the network was associated with individual's sustained participation in the year following the year of the study. We discuss these key findings followed by implications for policy, research, practice, and recommendations for future research.

\section{Key Findings for the Nature of the Conversations Taking Place Through \#NGSSchat}

\#NGSSchat provides an example of how social media-based networks can allow for substantive conversations around education reform - in this case, an ambitious science education transformation effort. We found that conversations that we considered to be sense-making or focused on NGSS or science education topics or problems, were commonplace: there were 1,597 unique sense-making conversations, comprising nearly one-third of all of the conversations that took place through \#NGSSchat. Considering only those conversation threads with two or more tweets (and so not considering posts that received no replies), sense-making conversations comprised nearly two-thirds of the conversations. In addition to being frequent, the vast majority of participants were a part of these substantive conversations; 205 of the 247 participants (or $83 \%$ ) were involved in one or more sense-making conversations. In light of the importance of conversations, especially those that are situated in the context and problems of practice stakeholders - especially teachers - face (Coburn, 2001; Horn \& Little, 2010; Horn et al., 2020; Penuel et al., 2013), for professional sense-making about reforms, the high proportion of sensemaking conversations may be a critical part of why individuals value \#NGSSchat — and for supporting the balanced involvement and sustained participation we discuss later.

We believe that the alignment of the chat questions with the tenets and practices of the NGSS likely was an important support for these substantive (sense-making or transformational) conversations. Many of the questions that moderators asked to structure \#NGSSchat chats called on participants to engage in substantive interactions about NGSS (see Table 1 for example questions). Additionally, the high proportion of sense-making conversations suggests an especially notable use (and role for) social media. Instead of simply an avenue for transmission of information from moderators to participants (Staudt Willet, 2019) — which is likely insufficient to support substantive conversations-\#NGSSchat appears to provide opportunities for sense-making conversations for many of its participants. Moreover, due to the strong alignment between the chat questions and NGSS, this sensemaking is likely to be productive. Last, because social media can provide opportunities for individuals to participate in conversations that they otherwise would or could not (Lantz-Andersson et al., 2019; Krutka et al., 2016), these conversations may be especially valuable to participants who are beginning to make sense of how the NGSS might relate to (and inform) efforts to improve science teaching and learning in their state, district, or school.

In addition to the importance of sense-making conversations, past research argues that conversations are more productive when they are carefully facilitated (Andrews-Larson et al., 2017) - like those that take place through \#NGSSchat are - and when they help those involved to align ideas about reforms with stakeholders' practice (Borko, 2004; Horn \& Little, 2010), as sense-making conversations, especially those that involve multiple stakeholders, may afford. Given how \#NGSSchat was designed, and the frequency of sense-making conversations, we 
argue that an important part of the value of social media-based networks such as \#NGSSchat is the open and varied conversations can take place. We think this is the case even when ideas that question (or diverge from) the NGSS are discussed, as such conversations can still provide opportunities to collaboratively make sense of their and others' ideas about the changes called for in reform efforts (Rosebery et al., 2010). Just as science education researchers have argued for valuing sensemaking in science classrooms, not simply correctness (Haverly et al., 2020; Schwarz et al., 2017) — and as policy scholars have argued in the context of instructional shifts (Coburn, 2001; Windschitl, 2006), there is value in providing opportunities for sensemaking about reforms among educators and other stakeholders in science education.

We also note that while many of the other conversations that took place were transactional, very few conversations were off-topic, or unrelated to the NGSS. While not sensemaking (or transformative), transactional conversations, which we found were often more social, may help participants to build a sense of belonging and community that is important for networks in any setting (Shulman \& Sherin, 2004), but is perhaps valued in informal networks (Bucher \& Fiseler, 2017; Fischer et al., 2019; Lantz-Andersson et al., 2018; Trust et al., 2016). In other words, social conversations matter, too, as we discuss further in the context of the next set of key findings. In summary of key findings from this study about substantive conversations, while we cannot say to what extent these conversations are representative of all informal networks, including others in science education, these findings suggest that the substantive conversations taking place through \#NGSSchat may support stakeholders from a variety of roles to make sense of their practice in light of the broad changes called for in the NGSS.

\section{Key Findings for the Extent of the Involvement of Multiple Stakeholders}

Individuals from a variety of professional roles and states at different stages of adopting the NGSS participated in \#NGSSchat, even in the 2014-2015 and 2015-2016 years when fewer states had adopted the standards than at present. Participation in \#NGSSchat was from individuals from a variety of professional roles, particularly teachers, who made up more than one-third of the 247 participants, but also administrators (20\% of participants) and researchers ( $7 \%$ of participants). This heterogeneity of professional roles was significant given past research that highlights how challenging it is for educational stakeholders in different roles to coordinate their work in schools, districts, and Universities (Coburn \& Stein, 2010; Cohen et al., 2007; Peurach et al., 2019; Penuel et al., 2013). Moreover, this heterogeneity is important in that stakeholders from multiple roles could see themselves as active participants because of the involvement of others with whom they share a key (in this context) personal characteristic, their professional role; in other words, homophily could contribute to not only researchers and administrators, but also teachers to choose to be involved in this network (Spillane et al., 2012).

That individuals from different roles were involved may mean that potential access to resources that can drive reform efforts may exist (Cobb et al., 2018; Stiles et al., 2017). Importantly, that many teachers were involved may also mean that conversations are likely to provide opportunities to develop an understanding of NGSS at the classroom level, an important feature of conversations for individuals in any role, but perhaps especially so for teachers (Horn \& Little, 2010). Finally, we note that the inclusion of multiple stakeholders may relate to and expand the relevance of the findings related to the presence of substantive conversations: because conversations were varied in nature (from sense-making to more transactional and social) and that nearly two-fifths of participants were teachers, it could be that \#NGSSchat served as a welcoming community for teachers, who chose to participate both because it advanced their professional goals (i.e., to learn more about the NGSS) and their desire to interact 
with others interested in changing their practice and the practice of others. In this context, we note that informal networks like \#NGSSchat may be especially useful for supporting teachers to feel like they can take (calculated) risks in their practice - tasks that may be difficult to take in the setting of one's school or district, for example (Krutka et al., 2016). Informal networks may also help participants who are not teachers to better understand the realities of classrooms in relation to large-scale reforms.

In terms of balanced participation, we found that three roles were especially prominent in terms of both initiating, or sending, and being the recipients of, or receiving, replies as a part of conversations. These three roles were researchers, administrators, and teachers. That individuals from these roles were prominent where it comes to being involved in conversations suggests that multiple stakeholders not only participate in \#NGSSchat but, also, that the resources particular to them and their professional role may be available to others, which supports reform stakeholders to develop a shared understanding (Penuel et al., 2011) and trust (López Turley \& Stevens, 2015), both of which can be uncommon - especially in collaborations between researchers and practitioners (Coburn, 2001; Farrell et al., 2019; Windschitl, 2006). That teachers both send and receive replies at comparable rates to administrators and researchers in this network is notable, as we discuss more as a key implication.

\section{Key Findings About the Sustainability of Participation in \#NGSSchat Over Time}

Finally, how long individuals participate in professional learning opportunities is important (Garet et al., 2001; Desimone, 2009); this consideration may be especially important in informal networks in which individuals voluntarily choose to participate (or to stop; LantzAndersson et al., 2018; Veletsianos, 2017). We found that teachers and administrators were more likely to actively participate in \#NGSSchat in the subsequent year, while researchers and organizations were not likely to sustain their involvement. Additionally, how exposed individuals were to both transactional and substantive conversations (accounting for how central participants in them were) was associated with greater sustained participation. Specificallyand in line with past research on participation in the education-wide hashtag \#edchat (Xing \& Gao, 2018)—we found that involvement in more transactional and substantive conversations predicted greater sustained participation, but that the relationship between involvement in transactional conversations and sustained participation was even greater than that for substantive conversations. If involvement in transactional conversations can support individuals to feel like they belong (e.g. Lantz-Andersson et al., 2018), perhaps this sense of belonging and community - in combination with involvement in the substantive conversations that provide access to resources - is what causes individuals (particularly teachers, given the high proportion of participants who were teachers and the findings showing that they, especially, are likely to sustain their participation) choose to continue to participate in \#NGSSchat over multiple years.

\section{Implications}

Implications for Research. \#NGSSchat was found to support not only deep conversations but also conversations of a variety of types. Moreover, it invites stakeholders from a variety of professional roles, and, importantly, seems to afford uncommon access (Coburn \& Stein, 2010) to them: For a researcher to access the insights of teachers, some who are leaders (and pioneers) concerning science teaching and learning in their schools, districts, and states, or for an administrator to pose questions or share concerns with researchers, some who served on the committee to write the Framework for K-12 Science Education (NRC, 2012), is uncommon, and so highlights one of the unique affordances of social media, the resources (Carpenter \& Krutka, 2014b) and professional networks (Trust et al., 2016) can provide access to. Particularly 
for the NGSS - a nationwide reform effort present in all but six states (representing more than $70 \%$ of U.S. students) as of the time of this writing (National Science Teachers Association, 2020) — networks such as \#NGSSchat may allow resources and professional networks to be more widespread and geographically distributed than they would be were such technology-based networks unavailable. In this context, establishing not only the potential of \#NGSSchat and other networks to support reform efforts, but also to investigate how their use may have shaped the particular ways in which this reform effort has developed and been implemented in practice.

Key characteristics collectively distinguish \#NGSSchat from other social media-based and informal professional networks (e.g., Greenhow et al., 2019; Lantz-Andersson et al., 2019): 1) the presence of different types of conversations, 2) access to stakeholders from different roles and balanced participation, as well as 3 ) the sustained participation of participants (especially administrators and teachers). While past research about professional networks and social media in education have pointed out their independent benefits, \#NGSSchat seems to demonstrate how the characteristics we explored might work together to support a nationwide reform effort. Consequently, another implication of this study concerns what those who are supporting other networks (including face-to-face networks) might do differently in light of the roles of networks like \#NGSSchat that are supported not by geographic proximity, but, rather, an affinity between individuals (Rosenberg et al., 2016; Gee, 2004) and their collective participation in conversations about the NGSS and science education (Garet et al., 2001). In particular, such networks may profitably incorporate multiple stakeholders and provide them with opportunities to interact on more equal grounds - whether that be through social media or carefully designed questions (such as those used by the moderators of \#NGSSchat to structure the chats) to interact in any setting. In this way, \#NGSSchat suggests new visions for how to address a persistent challenge for those seeking to reform education (Coburn, 2001; Peurach et al., 2019), implementing changes in complex systems that require the collective participation of multiple stakeholders.

Implications for Practice. These findings may have implications for science teachers and science teacher educators. In light of the way \#NGSSchat has been used, we think researchers and teacher educators should consider the potential in social media to support sensemaking about the NGSS and other science education topics, questions, and issues in an open and accessible way. Moreover, we think that researchers and teacher educators could see benefits to participating in these networks, as doing so provides the opportunity for science teacher educators to contribute to and shape the conversation about science teaching and learning and how to improve science education, whether in the U.S. or in other countries around the world, where similar networks often already-exist or could be developed and supported. Last, we think that social media-based networks may be useful alongside professional development efforts for teachers and others, as doing so may leverage some of the affordances on such networks alongside the affordances of face-to-face professional learning communities, which might be better tailored to local issues.

Methodological Implications. While the use of social network analysis in science education research is growing (e.g., Fortus et al., 2019; Navy et al., 2019), it remains limited, and much of the research on technology- and social media-based networks is primarily descriptive (Macià \& Garcia, 2016). While descriptive uses of social network analysis are valuable, if researchers wish to design or impact social networks, a focus upon social network processes may be particularly important - including selection processes to interrogate who interacts with whom and influence processes to understand how involvement in interactions or relationships matter. In this study, we explored \#NGSSchat with methods more commonly used to study face-to-face 
networks (Coburn et al., 2010; Frank et al., 2013; Horn et al., 2020; Spillane et al., 2012) that allowed us to understand how balanced the participation of individuals was and how participants' interactions affected their involvement in the subsequent year.

\section{Limitations and Recommendations for Future Research}

Analyzing a digital network such as \#NGSSchat on Twitter has strengths as well as weaknesses - and limitations - relative to face-to-face networks. There are things that we could do with the data we had, such as look back at \#NGSSchat during a time in which many states were adopting the standards, and to gain insights into the conversation taking place, the participants involved in them and their participation, and even - using longitudinal data - their sustained participation. While the longitudinal data set was a strength of this study, it also presented limitations. By accessing tweets that were archived through the Storify platform, we knew that some tweets may not have been archived, which may have led to a biased selection of tweets (in favor of those with more conversations). However, additional analyses revealed that most of the original data from the chats were archived and therefore accessed and used in this study, while most of the data from the non-chat time were not available (Borchers et al., 2020).

Second, while we focused on professional roles and geographical locations, heterogeneity in the voices of participants could concern much more. Particularly noteworthy is the absence of any measures about individuals - including their grade level and their identity —in our analyses. This is important because it may speak not only to how \#NGSSchat functions as a network, but now inclusive and representative of a network it may be, a key question pointed out in a recent review of digital networks (Lantz-Andersson et al., 2018). Future research may address this limitation by considering the merits of research methods other than social network analysis (e.g., surveys) to gauge how representative \#NGSSchat is of the broader science education domain, and to make suggestions for how to improve the network.

Finally, we note that the authors are familiar with the \#NGSSchat network. While we are not the organizers for the chat and were not involved in its creation, one of us has led one of the chats, and others have participated in chats, including chats that were analyzed in this study. This familiarity was important as it helped us to recognize potentially positive aspects of the network; it also gave us particular insight into the specific individuals who served as moderators and participants in these chats. However, this position could also be a negative, as it was concomitant with an affinity toward the network and its potential benefits, and so we were careful to frame this study theoretically and to carry out the analyses without aiming for specific results (or levels of statistical significance). Lastly, we note that this positionality was related to our decision to anonymize example tweets and to carefully share data. An issue with Twitter data is that while it is in the public domain, many \#NGSSchat participants posted without thinking that their post would be used for research--and, they may not have participated had they known their activity would be used for such purposes (Fiesler \& Proferes, 2018). Accordingly, we chose to anonymize the example tweets we included and share the analytic code ${ }^{9}$ associated with this study, but not the data, which we stated that we will share upon request. We recommend to other researchers studying \#NGSSchat or other educational networks to consider this, as well, especially when familiar with the network and therefore inclined to share about it.

\section{Conclusion}

\#NGSSchat demonstrates similarities and distinctive features relative to other face-toface and social media-based networks, and while few networks possess the same characteristics as \#NGSSchat, other contexts are likely emerging where science education stakeholders can find

\footnotetext{
${ }^{9} \mathrm{https://osf.io/9ex7 \textrm {k } /}$
} 
common ground to shape its future. Such new — often digital - contexts - especially those that foster substantive conversation, balanced involvement, and sustained participation - should, we think, be sought out, scrutinized, and supported, as they can suggest new visions for how to implement ambitious change efforts in complex educational systems. 


\section{References}

Anderson, C. W., de los Santos, E. X., Bodbyl, S., Covitt, B. A., Edwards, K. D., Hancock, J. B., ... \& Welch, M. M. (2018). Designing educational systems to support enactment of the Next Generation Science Standards. Journal of Research in Science Teaching, 55, 10261052. https://doi.org/10.1002/tea.21484

Andrews-Larson, C., Wilson, J., \& Larbi-Cherif, A. (2017). Instructional improvement and teachers' collaborative conversations: The role of focus and facilitation. Teacher College Record, 119, 1-37

Bereiter, C. (2014). Principled practical knowledge: Not a bridge but a ladder. Journal of the Learning Sciences, 23(1), 4-17.

Booth, S. (2012). Cultivating knowledge sharing and trust in online communities for educators. Journal of Educational Computing Research, 47(1), $1 \mathrm{e} 31$.

Borchers, C., Rosenberg, J. M., \& Fischer, C. (2020). An examination of the \#NGSSchat Storify database. OSF Preprints. https://doi.org/10.31219/osf.io/4tafx

Borko, H. (2004). Professional development and teacher learning: Mapping the terrain. Educational Researcher, 33(8), 3-15.

Bourdieu, P. (1980). Le capital social: notes provisoires. Actes de la recherche en sciences sociales, 31(1), 2-3.

Bucher, E., \& Fieseler, C. (2017). The flow of digital labor. New Media \& Society, 19(11), $1868 \mathrm{e} 1886$.

Bürkner, P. C. (2017). brms: An R package for Bayesian multilevel models using Stan. Journal of Statistical Software, 80(1), 1-28.

Carolan, B. V. (2014). Social network analysis and education: Theory, methods, and applications. Thousand Oaks, CA: SAGE.

Carpenter, J. P., \& Krutka, D. G. (2014a). Chat it up. Learning \& Leading with Technology, 41(5), 10-15.

Carpenter, J. P., \& Krutka, D. G. (2014b). How and why educators use Twitter: A survey of the field. Journal of Research on Technology in Education, 46, 414-434. doi:10.1080/15391523.2014.925701

Cherbow, K., McKinley, M. T., McNeill, K. L., \& Lowenhaupt, R. (2020). An analysis of science instruction for the science practices: Examining coherence across system levels and components in current systems of science education in K-8 schools. Science Education, 104(3), 446-478.

Cobb, P., Jackson, K., Henrick, E., Smith, T. M., \& the MIST Team. (2018). Systems for instructional improvement: creating coherence from the classroom to the district office. Cambridge, MA: Harvard Education Press.

Coburn, C. E. (2001). Collective sensemaking about reading: How teachers mediate reading policy in their professional communities. Educational Evaluation and Policy Analysis, $23,145-170$.

Coburn, C. E., \& Stein, M. K. (2010). Research and practice in education: Building alliances, bridging the divide. Rowman \& Littlefield Publishers.

Coburn, C. E., Choi, L., \& Mata, W. S. (2010). "I would go to her because her mind is math": Network formation in the context of district-based mathematics reform. In J. Daly (Ed.) Social network theory and educational change (pp. 33-50). Harvard Education Press. 
Coburn, C. E., Russell, J. L., Kaufman, J. \& Stein, M. K. (2012) Supporting sustainability: Teachers' advice networks and ambitious instructional reform. American Journal of Education, 119, 137-182.

Desimone, L. M. (2009). Improving impact studies of teachers' professional development: Toward better conceptualizations and measures. Educational Researcher, 38(3), 181-199.

Ebner, M., Holzinger, A., \& Catarci, T. (2005). Lurking: An underestimated human-computer phenomenon. MultiMedia, IEEE, 12, 70-75.

Edelmann, N. (2013). Reviewing the definitions of "lurkers" and some implications for online research. Cyberpsychology, Behavior, and Social Networking, 16, 645-649. https://doi.org/10.1089/cyber.2012.0362

Farrell, C. C., Harrison, C., \& Coburn, C. E. (2019). What the hell is this, and who the hell are you?" role and identity negotiation in research-practice partnerships. AERA Open, 5(2). https://journals.sagepub.com/doi/full/10.1177/2332858419849595

Fiesler, C., \& Proferes, N. (2018). "Participant" perceptions of Twitter research ethics. Social Media + Society, 4(1), 1-14.

Fischer, C., Fishman, B., \& Schoenebeck, S. (2019). New contexts for professional learning: Analyzing high school science teachers' engagement on Twitter. AERA Open, 5(4), 1-20. https://doi.org/10.1177/2332858419894252

Fortus, D., Kubsch, M., Bielik, T., Krajcik, J., Lehavi, Y., Neumann, K., ... \& Touitou, I. (2019). Systems, transfer, and fields: Evaluating a new approach to energy instruction. Journal of Research in Science Teaching, 56(10), 1341-1361.

Frank, K. A. (1998). Chapter 5: Quantitative methods for studying social context in multilevels and through interpersonal relations. Review of Research in Education, 23(1), 171-216.

Frank, K. A. (2009). Quasi-ties: Directing resources to members of a collective. American Behavioral Scientist, 52, 1613-1645.

Frank, K. A., Muller, C., \& Mueller, A. S. (2013). The embeddedness of adolescent friendship nominations: The formation of social capital in emergent network structures. American Journal of Sociology, 119(1), 216-253.

Frank, K. A., Penuel, W. R., \& Krause, A. (2015). What is a "good" social network for policy implementation? The flow of know-how for organizational change. Journal of Policy Analysis and Management, 34, 378-402.

Frank, K. A., Xu, R., \& Penuel, W. R. (2018). Implementation of evidence-based practice in human service organizations: Implications from agent-based models. Journal of Policy Analysis and Management, 37, 867-895.https://doi.org/10.1002/pam.22081

Frank, K. A., Zhao, Y., \& Borman, K. (2004). Social capital and the diffusion of innovations within organizations: The case of computer technology in schools. Sociology of Education, 77, p. 148-171.

Frumin, K., Dede, C., Fischer, C., Fishman, B., Eisenkraft, A., Foster, B., Levy, A., Lawrenz, F., $\&$ McCoy, A. (2018). Adapting to large-scale changes in Advanced Placement biology, chemistry, and physics: The impact of online teacher communities. International Journal of Science Education, 40(4), 397-420. https:/doi.org/10.1080/09500693.2018.1424962

Garet, M. S., Porter, A. C., Desimone, L., Birman, B. F., \& Yoon, K. S. (2001). What makes professional development effective? Results from a national sample of teachers. American Educational Research Journal, 38(4), 915-945.

Gelman, A., \& Hill, J. (2006). Data analysis using regression and multilevel/hierarchical models. Cambridge University Press. 
Gee, J. P. (2004). Situated language and learning: A critique of traditional schooling. Psychology Press.

Goldring, E., Huff, J., Spillane, J. P., \& Barnes, C. (2009). Measuring the learning-centered leadership expertise of school principals. Leadership and Policy in Schools, 8(2), $197-$ 228.

Goode, J., Margolis, J., \& Chapman, G. (2014, March). Curriculum is not enough: The educational theory and research foundation of the exploring computer science professional development model. In Proceedings of the 45th ACM Technical Symposium on Computer Science Education (pp. 493-498). Association for Computing Machinery.

Greenhalgh, S. P., Rosenberg, J. M., \& Wolf, L. G. (2016). For all intents and purposes: Twitter as a foundational technology for teachers. E-Learning and Digital Media, 13, 81-98. https://doi.org/10.1177/2042753016672131

Greenhalgh, S. P., Rosenberg, J. M., Staudt Willet, K. B., Koehler, M. J., \& Akcaoglu, M. (2020). Identifying multiple learning spaces within a single teacher-focused Twitter hashtag. Computers \& Education. https://doi.org/10.1016/j.compedu.2020.103809

Greenhalgh, S. P., Staudt Willet, B. K., Rosenberg, J. M., \& Koehler, M. J. (2018). Tweet, and we shall find: Using digital methods to locate participants in educational hashtags. TechTrends, 62, 501-508. https://doi.org/10.1007/s11528-018-0313-6

Greenhow, C., Galvin, S. M., \& Staudt Willet, K. B. (2019). What should be the role of social media in education?. Policy Insights from the Behavioral and Brain Sciences, 6, 178-185.

Haverly, C., Calabrese Barton, A., Schwarz, C. V., \& Braaten, M. (2020). "Making Space": How Novice Teachers Create Opportunities for Equitable Sense-Making in Elementary Science. Journal of Teacher Education, 71(1), 63-79.

Horn, I. S., \& Little, J. W. (2010). Attending to problems of practice: Routines and resources for professional learning in teachers' workplace interactions. American Educational Research Journal, 47, 181-217.

Horn, I., Garner, B., Chen, I. C., \& Frank, K. A. (2020). Seeing Colleagues as Learning Resources: The Influence of Mathematics Teacher Meetings on Advice-Seeking Social Networks. AERA Open, 6(2), 2332858420914898.

Kimmons, R., \& Veletsianos, G. (2016). Education scholars' evolving uses of twitter as a conference backchannel and social commentary platform. British Journal of Educational Technology, 47, 445-464.

Koc, Y., Peker, D., \& Osmanoglu, A. (2009). Supporting teacher professional development through online video case study discussions: An assemblage of preservice and inservice teachers and the case teacher. Teaching and Teacher Education, 25(8), 1158-1168.

Krutka, D. G., Carpenter, J. P., \& Trust, T. (2016). Elements of engagement: A model of teacher interactions via professional learning networks. Journal of Digital Learning in Teacher Education, 32(4), 150e158. https://doi.org/10.1080/ 21532974.2016.1206492

Lantz-Andersson, A., Lundin, M., \& Selwyn, N. (2018). Twenty years of online teacher communities: A systematic review of formally-organized and informally-developed professional learning groups. Teaching and Teacher Education, 75, 302-315.

Little, J. W., \& Horn, I. S. (2007). Normalizing'problems of practice: Converting routine conversation into a resource for learning in professional communities. In L. Stoll \& K. S. Louis (Eds.), Professional learning communities: Divergence, depth, and dilemmas (pp. 79-92). New York, NY: Open University Press. 
López Turley, R. N., \& Stevens, C. (2015). Lessons from a school district-university research partnership: The Houston Education Research Consortium. Educational Evaluation and Policy Analysis, 37(1), 6S-15S.

Lowenhaupt, R., \& McNeill, K. L. (2019). Subject-specific instructional leadership in K8 schools: The supervision of science in an era of reform. Leadership and Policy in Schools, 18, 460-484. https://doi.org/10.1080/15700763.2018.1453937

Macià, M., \& García, I. (2016). Informal online communities and networks as a source of teacher professional development: A review. Teaching and Teacher Education, 55, 291-307.

Marshall, S. L. (2018). Elementary principal networks: Sensemaking of science education policy post-NCLB. Michigan State University.

McDonald, S. P., \& Kelly, G. J. (2012). Beyond argumentation: Sense-making discourse in the science classroom. In M. S. Khine (Ed.), Perspectives on scientific argumentation (pp. 265-281). Springer, Dordrecht.

McFarland, D. A., Lewis, K., \& Goldberg, A. (2015). Sociology in the era of big data: The ascent of forensic social science. The American Sociologist, 47, 12-3. https://doi.org/10.1007/s12108-015-9291-8

Michaels, S., \& O’Connor, C. (2012). Talk science primer. Cambridge, MA: TERC.

Miles, M., Huberman, A., \& Saldana, J. (2014). Qualitative data analysis (3rd ed.). Thousand Oaks, CA: Sage.

National Research Council [NRC]. (2012). A framework for K-12 science education: Practices, crosscutting concepts, and core ideas. Washington, DC: The National Academies Press.

National Research Council [NRC]. (2015). Guide to implementing the next generation science standards. Washington, DC: National Academies Press. https://doi.org/10.17226/18802

National Science Teachers Association (2020). About the Next Generation Science Standards. https://ngss.nsta.org/About.aspx

Navy, S. L., Nixon, R. S., Luft, J. A., \& Jurkiewicz, M. A. (2020). Accessed or latent resources? Exploring new secondary science teachers' networks of resources. Journal of Research in Science Teaching, 57(2), 184-208.

NGSS Lead States (2013). Next generation science standards: For states, by states. http://www.nextgenscience.org/

Pederson, T. L. (2018). ggraph: An implementation of grammar of graphics for graphs and networks. R package version 2.0.0. https:/CRAN.R-project.org/package=ggraph

Penuel, W. R., Fishman, B. J., Haugan Cheng, B., \& Sabelli, N. (2011). Organizing research and development at the intersection of learning, implementation, and design. Educational Researcher, 40(7), 331-337.

Penuel, W. R., Frank, K. A., Sun, M., Kim, C. M., \& Singleton, C. A. (2013). The organization as a filter of institutional diffusion. Teachers College Record, 33.

Penuel, W. R., Harris, C. J., \& DeBarger, A. H. (2015). Implementing the Next Generation Science Standards. Phi Delta Kappan, 96(6), 45-49. https://doi.org/10.1177/0031721715575299

Penuel, W. R., Lin, Q., Marshall, S., Anderson, C.W., Frank, K.A. (2018). Building networks to support effective use of science curriculum materials in the Carbon TIME Project. In S. A. Yoon \& K. J. Baker-Doyle (Eds.), Networked by design: Interventions for teachers to develop social capital. New York, NY: Routledge.

Peurach, D. J., Cohen, D. K., Yurkofsky, M. M., \& Spillane, J. P. (2019). From mass schooling to education systems: Changing patterns in the organization and management of 
instruction. Review of Research in Education, 43, 32-67.

https://doi.org/10.3102/0091732X18821131

Portes, A. (2000). The two meanings of social capital. In Sociological forum (Vol. 15, No. 1, pp. 1-12). Kluwer Academic Publishers-Plenum Publishers.

Putnam, R. T., \& Borko, H. (2000). What do new views of knowledge and thinking have to say about research on teacher learning? Educational researcher, 29(1), 4-15.

Raudenbush, S. W., \& Bryk, A. S. (2002). Hierarchical linear models: Applications and data analysis methods (2nd ed.). Newbury Park, CA: Sage.

Rosebery, A. S., \& Warren, B. (2008). Teaching science to English language learners: Building on students'strengths. Arlington, VA: National Science Teachers Association Press

Rosebery, A. S., Ogonowski, M., DiSchino, M., \& Warren, B. (2010). "The coat traps all your body heat": Heterogeneity as fundamental to learning. Journal of the Learning Sciences, 19(3), 322-357.

Rosenberg, J. M., Greenhalgh, S. P., Koehler, M. J., Hamilton, E., \& Akcaoglu, M. (2016). An investigation of State Educational Twitter Hashtags (SETHs) as affinity spaces. ELearning and Digital Media, 13(1-2), 24-44. http://dx.doi.org/10.1177/2042753016672351

Rosenberg, J.M., Greenhalgh, S.P., Graves Wolf, L. \& Koehler, M.J. (2017). Strategies, use, and impact of social media for supporting teacher community within professional development: The case of one urban STEM program. Journal of Computers in Mathematics and Science Teaching, 36(3), 255-267. https://www.learntechlib.org/primary/p/180387/

Sandoval, W. A., Kwako, A. J., Modrek, A. S., \& Kawasaki, J. (2018). Patterns of classroom talk through participation in discourse- focused teacher professional development.

Proceedings of the 13th International Conference of the Learning Sciences, 2, 760-767. London, UK: International Society of the Learning Sciences.

Schwarz, C. V., Passmore, C., \& Reiser, B. J. (2017). Helping students make sense of the world using next generation science and engineering practices. NSTA Press.

Shelton, T., \& Ende, F. (2015). Commentary: Chatting up a deeper understanding of NGSS. NSTA Reports, 26. http://static.nsta.org/pdfs/nstareports/nstareports201505.pdf

Shulman, L. S., \& Sherin, M. G. (2004). Fostering communities of teachers as learners: Disciplinary perspectives. Journal of Curriculum Studies, 36(2), 135-140.

Spillane, J. P., Kim, C. M., \& Frank, K. A. (2012). Instructional advice and information providing and receiving behavior in elementary schools: Exploring tie formation as a building block in social capital development. American Educational Research Journal, 49, 1112-1145.

Coburn, C. E. (2001). Collective sensemaking about reading: How teachers mediate reading policy in their professional communities. Educational Evaluation and Policy Analysis, 23(2), 145-170.

Staudt Willet, K. B. (2019). Revisiting how and why educators use Twitter: Tweet types and purposes in\# Edchat. Journal of Research on Technology in Education, 52, 216-233.

Stein, M. K., \& Coburn, C. E. (2008). Architectures for learning: A comparative analysis of two urban school districts. American Journal of Education, 114(4), 583-626.

Stiles, K. E., Mundry, S. E., \& DiRanna, K. (2017). Framework for leading next generation science standards implementation. San Francisco, CA: WestEd. 
Trust, T., Krutka, D. G., \& Carpenter, J. P. (2016). “Together we are better”: Professional learning networks for teachers. Computers \& Education, 102, 15-34.

van Bommel, J., Randahl, A. C., Liljekvist, Y., \& Ruthven, K. (2020). Tracing teachers' transformation of knowledge in social media. Teaching and Teacher Education, 87, 102958.

Veletsianos, G. (2017). Three cases of hashtags used as learning and professional development environments. TechTrends, 61, 284-292. https://doi.org/10.1007/s11528-016-0143-3

Wasserman, S., \& Faust, K. (1994). Social network analysis: Methods and applications (Vol. 8). Cambridge University Press.

Wesely, P. M. (2013). Investigating the community of practice of world language educators on Twitter. Journal of Teacher Education, 64(4), 305-318.

Wilhelm, A. G., Chen, I.-C., Smith, T. M., \& Frank, K. A. (2016). Selecting expertise in context: Middle school mathematics teachers' selection of new sources of instructional advice. American Educational Research Journal, 53, 456-491. https://doi.org/10.3102/0002831216637351

Windschitl, M. (2004). Folk theories of "inquiry:" How preservice teachers reproduce the discourse and practices of an atheoretical scientific method. Journal of Research in Science Teaching, 41(5), 481-512.

Windschitl, M. (2006). Why we can't talk to one another about science education reform. Phi Delta Kappan, 87, 384-355.

Xing, W., \& Gao, F. (2018). Exploring the relationship between online discourse and commitment in Twitter professional learning communities. Computers \& Education, 126, 388-398. https://doi.org/10.1016/j.compedu.2018.08.010

Zijlstra, B. J., Van Duijn, M. A., \& Snijders, T. A. (2006). The multilevel p2 model. Methodology, 2(1), 42-47. 
Figure S1

Histogram of the Number of Tweets per Participant for \#NGSSchat Participants

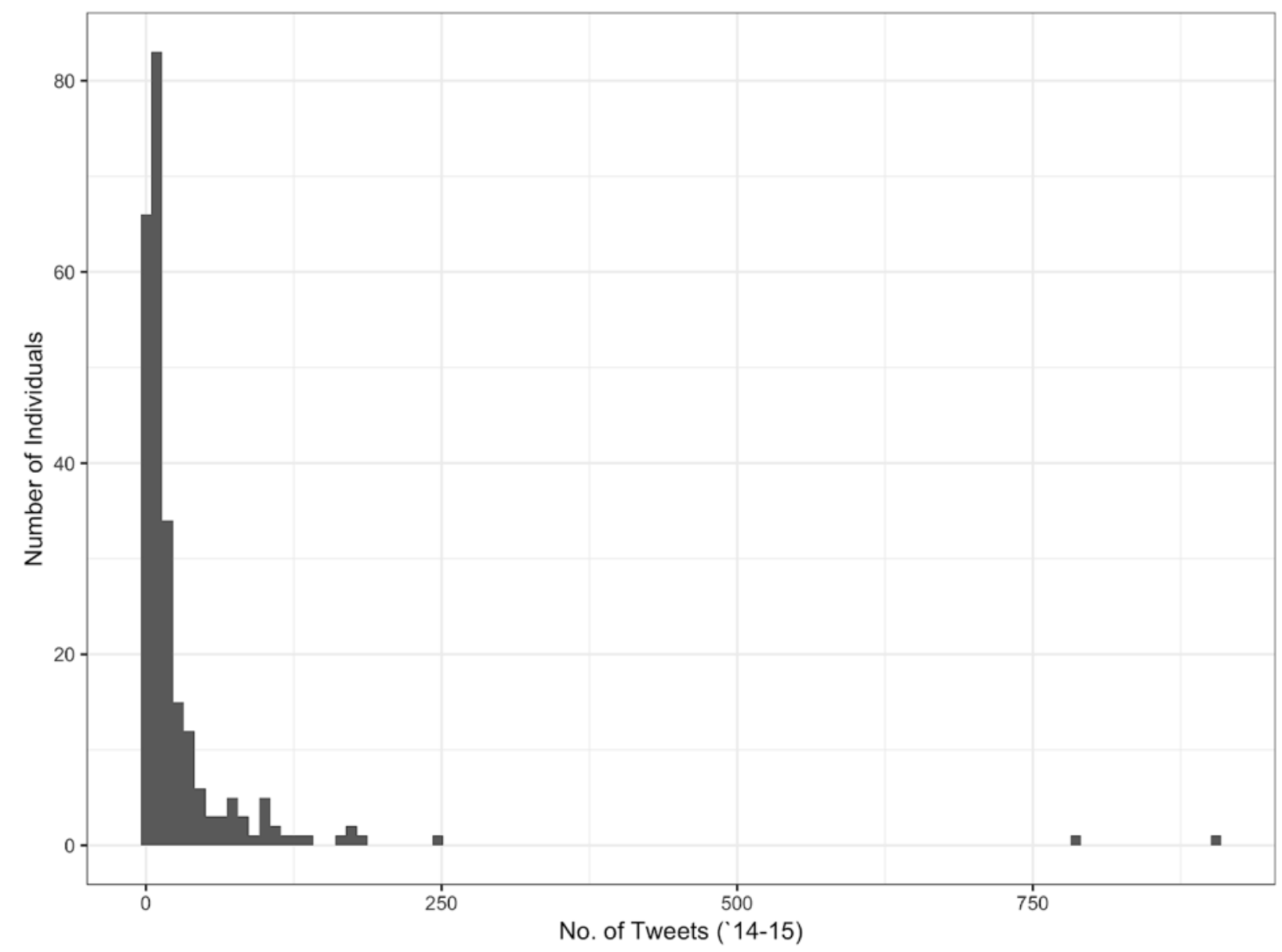




\section{Table S1}

Topics for Next Generation Science Standards Chats (During the 2014-2015 and 2015-2016 School Years)

\begin{tabular}{|c|c|}
\hline $\begin{array}{l}\text { Year of } \\
\text { Chat }\end{array}$ & Topic \\
\hline 2014 & Chat focused on the practice of constructing explanations and designing solutions. \\
\hline 2014 & Chat focused on the practice of engaging in argument from evidence. \\
\hline 2014 & Chat focused on the practice of obtaining, evaluating, and communicating evidence. \\
\hline 2014 & Chat focused on the interplay between NGSS and learner-focused PD. \\
\hline 2014 & $\begin{array}{c}\text { Chat focused on the three-dimensional nature of NGSS and what it means for science } \\
\text { education. }\end{array}$ \\
\hline 2014 & Chat focused on the STEM connections inherent in NGSS. \\
\hline 2014 & $\begin{array}{c}\text { Chat focused on \#NGSS and Implementation in conjunction with the NSTA Area } \\
\text { Conference. }\end{array}$ \\
\hline 2014 & $\begin{array}{c}\text { Chat focused on connections between informal and community-based science programs } \\
\text { and NGSS. }\end{array}$ \\
\hline 2015 & $\begin{array}{l}\text { Chat focused on the Framework for K-12 Science Education and its implications for } \\
\text { the NGSS. }\end{array}$ \\
\hline 2015 & Chat focused on the connections for learning that exist in, and outside of, NGSS. \\
\hline 2015 & $\begin{array}{l}\text { Chat focused on futurizing twentieth century science education practices and bringing } \\
\text { them up to speed with } \mathrm{N} \\
\text { GSS. }\end{array}$ \\
\hline 2015 & $\begin{array}{l}\text { LIVE FROM NSTA15! Chat focused on the power of a PLN, and how conferences and } \\
\text { chats can help build capacity to better education. }\end{array}$ \\
\hline 2015 & $\begin{array}{l}\text { Chat focused on the use of instructional videos from Teaching Channel and Official } \\
\text { NGSS to help educators begin thinking differently about the NGSS. Co-moderated with } \\
\text { assistance of Achieve and Teaching Channel! }\end{array}$ \\
\hline 2015 & Chat focused on scaffolding in the NGSS. \\
\hline 2015 & Chat focused on a look at a variety of progressions in NGSS. \\
\hline 2015 & Chat focused on a look at Appendix A, the shifts that set NGSS apart. \\
\hline 2015 & $\begin{array}{l}\text { Chat focused on a look at Appendix } \mathrm{C} \text {, which explores the college and career } \\
\text { connections in NGSS. }\end{array}$ \\
\hline 2015 & Chat focused on diving into PLN summer and science plans! \\
\hline 2015 & $\begin{array}{l}\text { Chat focused on science for all students, and was co-moderated with the assistance of } \\
\text { Okhee Lee, Emily Miller, and Rita Januszyk. }\end{array}$ \\
\hline 2015 & Chat focused on Appendix $G$ and the Cross Cutting Concepts. \\
\hline 2015 & Chat focused on the use of the newly released evidence statements for NGSS. \\
\hline 2015 & Chat focused in more detail on the evidence statements for NGSS. \\
\hline 2015 & $\begin{array}{l}\text { Chat centered on focusing on phenomena in NGSS and was co-moderated by TJ } \\
\text { McKenna. }\end{array}$ \\
\hline 2015 & In collaboration with \#Sci4AllSs, chat focused on a dive into the Framework. \\
\hline 2015 & $\begin{array}{l}\text { Chat focused on the Framework, and its focus on learning for all and was co-moderated } \\
\text { by Jaclyn Austin and Josh Hubbard. }\end{array}$ \\
\hline
\end{tabular}


2015

2015

2015

2015

2015

2015

2015

2015

2016

2016

2016

2016

2016

2016

2016

2016

2016

2016

Chat focused on summer learning and taking science back to school as 2015-2016 begins.

Chat focused on the Nature of Science and connections to, and within, NGSS.

Chat focused on assessment, and its place in NGSS.

Chat continued to focus on assessment, and its place in NGSS. Chat focused on organizational partnerships and the NGSS, live from KSTA. Chat focused on speaking, reading, and writing, and the connection to NGSS.

Chat focused on the road to adoption of the NGSS. Chat focused on mid-year reflections on instruction and practice regarding NGSS. Chat focused on New Year's resolutions and goals regarding NGSS.

Chat focused on edtech and the NGSS. Chat focused on professional learning and the NGSS.

Chat focused on the experience of learning, leading, and living, by NGSS. Chat focused on connecting scientists and practitioners through NGSS, and was moderated by@TJScience and@BMSScienceTeach. Chat focused on the cross cutting concepts, and in particular the patterns and cause/effect CCCs.

Chat focused on the cross cutting concepts, and in particular the scale, proportion, and quantity and systems/system models CCCs. Chat focused on \#NGSS and leadership. Chat focused on \#NGSS and storylines. Chat continued the focus on \#NGSS and storylines. 


\section{Table S2}

Questions for \#NGSSchat Chats (During the 2014-2015 School Year)

\begin{tabular}{|c|c|}
\hline $\begin{array}{l}\text { Order of } \\
\text { Question }\end{array}$ & Chat Question \\
\hline 1 & $\begin{array}{l}\text { Q1: How do you currently explore the practice of using math and computational } \\
\text { thinking with your students? \#NGSSchat }\end{array}$ \\
\hline 1 & $\begin{array}{l}\text { Q3: Making us of models is a practice in both the math and science standards. Why } \\
\text { is this so important? \#ngsschat }\end{array}$ \\
\hline 1 & $\begin{array}{l}\text { Q4: within the PEs, Quantity and Number are common crossovers between ccss and } \\
\text { ngss. Why are these so important? \#NGSSchat }\end{array}$ \\
\hline 1 & $\begin{array}{l}\text { Q5. What resources focused on incorporating math do you currently utilize? Please } \\
\text { share! \#NGSSchat }\end{array}$ \\
\hline 2 & Q1: How is an explanation similar/different from a solution? \#NGSSchat \\
\hline 2 & $\begin{array}{l}\text { Q2: What strategies do you use with learners to help them become more proficient } \\
\text { "explainers" and "designers"? \#NGSSchat }\end{array}$ \\
\hline 2 & $\begin{array}{l}\text { Q3. How do you use this practice for assessment purposes? What evidence of } \\
\text { learning do you tend to seek? \#NGSSchat }\end{array}$ \\
\hline 2 & $\begin{array}{l}\text { Q4 What resources focused on constructing explanations and designing solutions do } \\
\text { you currently utilize? Please share! \#NGSSchat }\end{array}$ \\
\hline 2 & $\begin{array}{l}\text { Q5: What feedback do you provide students to move their explanations and } \\
\text { solutions thinking forward? \#ngsschat }\end{array}$ \\
\hline 2 & $\begin{array}{l}\text { Q6 How can you incorporate this practice into the work you do focusing on other } \\
\text { practices? \#NGSSchat }\end{array}$ \\
\hline 3 & $\begin{array}{c}\text { Q1: Why is the practice of argumentation so important to the fields of science and } \\
\text { engineering? \#NGSSchat }\end{array}$ \\
\hline 3 & $\begin{array}{c}\text { Q2: What norms need to be present in the classroom to support argumentation and } \\
\text { critique? \#NGSSchat }\end{array}$ \\
\hline 3 & $\begin{array}{l}\text { Fred Q3: How are you currently utilizing the practice of argumentation with your } \\
\text { students? \#NGSSchat }\end{array}$ \\
\hline 3 & $\begin{array}{l}\text { Q4: What are the biggest challenges students face when engaging in an argument } \\
\text { from evidence? How do you support? \#NGSSchat }\end{array}$ \\
\hline 3 & $\begin{array}{l}\text { Q5: How do you support learners in developing prof. in critiquing arguments? } \\
\text { Considering counterclaims? Revising arguments? \#NGSSchat }\end{array}$ \\
\hline 3 & $\begin{array}{l}\text { Q6: How do you differentiate the practices of explanation and argument? How is } \\
\text { this practice being tied to the other 7? \#NGSSchat }\end{array}$ \\
\hline 4 & $\begin{array}{l}\text { Q1 The practice of Obtaining, Evaluating, and Communicating Information is as } \\
\text { much about literacy as sci/eng Why is this important? \#NGSSchat }\end{array}$ \\
\hline 4 & Q2: How are you currently building literacy skills in your classroom? \#NGSSchat \\
\hline 4 & $\begin{array}{c}\text { Q3: Why is "obtaining," "evaluating," and "communicating" so important to sci/eng } \\
\text { instruction? \#NGSSchat }\end{array}$ \\
\hline 4 & $\begin{array}{l}\text { Q4: Thinking back to the previous question, which skill do students tend to struggle } \\
\text { with most? Why? \#NGSSchat }\end{array}$ \\
\hline 4 & Q5. What role does technology/media play in supporting this practice? \#NGSSchat \\
\hline 5 & $\begin{array}{c}\text { Q1 2/2 What have been one of your "aha moments" concerning professional } \\
\text { learning and the \#NGSS ? \#NGSSchat }\end{array}$ \\
\hline
\end{tabular}


Q2.7 How do you approach discussions about curriculum building and redesign? \#NGSSchat (2/2)

Q2.7. A starting Q for many Ts is "How will \#NGSS change the sequence of courses?" \#NGSSchat (1/2)

Q3. A Guidepost to \#NGSS PD is ENGAGEMENT. How do you provide opptys for active learning, collaboration, discourse and reflection? \#NGSSchat

Q1. What have your Science PD workshops "looked like" so far? What are your participants engaged in? \#NGSSchat

\section{\#NGSSchat}

Q1. How do Science, Technology, Engineering, and Mathematics intersect to provide rich educational experiences? \#NGSSchat

Q2. What STEM initiatives are you currently exploring in your school, district, or informal program? \#NGSSchat

Q3. How do the \#NGSS signify a new direction for \#STEM education? What is the intersection between STEM and NGSS? \#NGSSchat

Q4. How does the 3D nature of \#NGSS make it easier (or harder) for creating a culture that supports STEM? \#NGSSchat

Q5. Why is it so important that our \#NGSS and \#STEM partnership begin in the primary grades? \#NGSSchat

Q1. What does \#NGSS \#implementation currently look like in your classroom/school/district? \#NGSSchat

Q2: How do the \#NGSS present opportunities for Technology in teaching and learning Science and Engineering? \#NGSSchat

Q3. How has networking leveraging technology helped you to better implement portions of the \#NGSS? \#NGSSchat

Q4. How have you used organizations and partnerships to learn and lead with \#NGSS in mind? (think \#CSTA and \#NSTA) \#NGSSchat

Q5. How are you incorporating various design models into your classroom NGSS implementation (UbD, 5E, others) \#NGSSchat

Q6: Where will you go next re: \#NGSS \#implementation? How will you get there? \#NGSSchat

Q1 One element of \#NGSS vision is coherent approach to science, K12. Share successes or barriers to achieving this vision. \#NGSSchat

Q3. A focus of Framework is "All children are born investigators." How do you (or can you) exhibit this in work with learners? \#NGSSchat

Q4 What can school leaders do to establish a climate that encourages science pedagogy as described in NGSS? via @richbacolor \#NGSSchat

Q1: The 3D nature of \#NGSS is all about making connections. How are you (or how can you) connect the 3 Dimensions? \#NGSSchat

Q2: \#NGSS connections exist inside each dimension. How does the scaffolded/banded nature of \#NGSS strengthen instruction? \#NGSSchat Q3: \#NGSS is connected to \#CCSS in part to help move science from supplement to staple. How do these connections shape your work? \#NGSSchat

Q4: Learners have to see that branches of science are closely intertwined. How are the CCCs successful (or not) at doing this? \#NGSSchat 
Q6: What steps are you taking (or do you plan to take this year) to help further interweave NGSS into the work that you do? \#NGSSchat

Q2 How can conferences like \#NSTA15 and/or \#NGSSchat help create a space for supporting understanding of \#NGSS? What opps do each create?

11 Q2: \#NGSSchat sparks ideas that lead to learning. I get so many links to resources I never knew existed and then shared my own. Win-Win.

11 Q3 Share how you are incorporating \#NGSS into your classroom learning OR what you hope to learn about \#NGSS and 3D learning. \#NGSSchat with? Where are you exceling? \#NGSSchat

Q4 What areas of \#NGSS implementation do you feel you need the most assistance

Q5 What=most imp idea you're reflecting on from \#NSTA15 Why? Once you leave \#NSTA15, what 1st step towards improving your pract? \#NGSSchat

Q6. If you are new to \#NGSSchat what did you enjoy most about our time together?

If not new, how did this tweetup help you as an educator?

Q1: These videos demonstrate teaching and learning through asking questions. How are you making the shift to focus on questioning? \#NGSSchat

Q2: How do you make the crosscutting concepts more explicit in your classroom?

\#NGSSchat

Q3: How do you encourage students to use multiple science and engineering practices to make sense of phenomena? \#NGSSchat

Q4: DCIs don't live in isolation. How does the convergence of core ideas help learners and educators internalize what science is? \#NGSSchat

Q5 It isn't just the 3D nature of the \#NGSS that is so critical, it's the integration of the 3Ds. How does this benefit students? \#NGSSchat

Ok everyone, Q6: How could you use this Teaching Channel series with your science colleagues? \#NGSSchat

Q1: Why is scaffolding so important when working with learners of all ages?

\#NGSSchat

Q2.1 follow-up How do you scaffold throughout a course? \#NGSSchat

Q2: In your current role, what/how do you scaffold within a unit? \#NGSSchat

Q3: Why is it so important for the DCIs to be scaffolded from elem. to HS? Pls give an example of this. \#NGSSchat

Q4: What best practices do you use to scaffold \#ngss learning in your classroom? \#NGSSchat

Q5: How can you best support scaffolding and progression convos in your school and district? Professional learning experiences? \#NGSSchat

Q5.1 follow-up - What resources can you share that you have designed or found to assist with scaffolding in science? \#NGSSchat :Q6 What does Science Discourse look like K-12? \#ngsschat

Q1: As NGSS promote 3-D learning, how do you use local contexts to enable ALL Ss in explaining phen and designing sol to problems? \#NGSSchat Q2. Prob solving focus of eng. has the potential to open science up to underserved Ss. How do you see eng. being a learning spark? \#NGSSchat 
14 Q3: When we "do" things, we embed them in our lives-Pick an SEP and share how it may increase the potential for learning for ALL Ss \#NGSSchat

14 Q4. In case study on economically disadvantaged Ss, what examples of strategies illustrate effective approaches to sci learning? \#NGSSchat

14 Q5: In the case study on English language learners, what examples of strategies illustrate effective approaches to Sci learning? \#NGSSchat

14 Q5 Did you know it takes 7-10 years for ELs to master the English language? \#NGSSchat

15 Q1: What is a Crosscutting Concept? What makes a concept truly across cutting?” \#NGSSchat

15 Q2 Why did the Framework writers choose to include the Crosscutting Concepts as one of the dimensions of \#NGSS? \#NGSSchat

15 Q3: How can the CCCs be seen as an organizational schema (much like a filing cabinet for Ss)? \#NGSSchat

15 Q4: How do the CCCs support the idea of "making thinking visible" in the classroom? \#NGSSchat

15 Q4 follow up What are some examples of ways to "make thinking visible" in the classroom? \#NGSSchat

15 Q5: What is 'coherence' in K12 education, and how do the CCCs support this? \#NGSSchat

15 Q6: For true 3D learning, CCCs need to be explicit in instruction and Ss need to

USE them How can we/do you accomplish? \#NGSSchat

16 Q1: What are some of the benefits/challenges you've found so far with benchmarks of the NGSS existing as performance expectations? \#NGSSchat

16 Q2: What is the purpose of the evidence statements? What add. info do they provide to the foundation boxes below a PE in \#NGSS \#NGSSchat

16 Q3: Evidence statements can be viewed as a magnification of the \#NGSS performance expectations (pg3) Explain this description. \#NGSSchat

16 Q5: The SEPs provide means by which students can make thinking visible; Why do ES' use SEPs as the organizing structure? \#NGSSchat

16 Q6: Share an evidence statement that you think truly supports a PE? Share why! OR Share a Q you have about Evidence statements \#NGSSchat

17 Q2When looking at an evid. statem. (like this http://t.co/8ERcjxH8Aj) why are the statements broken down into different components? \#NGSSchat

17 Q3: Share an ES from the physical science strand that gives insight into associated

$\mathrm{PE}$ and how the statement provides that insight \#NGSSchat

17 Q4: How could you use evidence statements to facilitate conversations in your PLN? \#NGSSchat

17 Q5: Why is the presence of Evidence Statements in the ETS branch so necessary? \#NGSSchat

Note. Only questions for chats from the 2014-2015 academic year (so and not the 2015-2016 academic year) are presented here. Some questions have fewer than six questions because the question was not archived; see Borchers et al. (2020). 


\section{Table S3}

Coding Frame for Professional Roles

\begin{tabular}{|c|c|c|}
\hline Code & Code Description & Group \\
\hline Teacher & Accounts belonging to teachers or educators & Teacher \\
\hline Administrator & $\begin{array}{l}\text { Accounts belonging to principals, superintendents, or other } \\
\text { school administrators }\end{array}$ & Support \\
\hline $\begin{array}{l}\text { Instructional } \\
\text { Support }\end{array}$ & $\begin{array}{c}\text { Accounts belonging to technology coaches, curriculum } \\
\text { developers, media specialists, etc. }\end{array}$ & Support \\
\hline $\begin{array}{l}\text { Educational } \\
\text { Researcher or } \\
\text { University Faculty }\end{array}$ & $\begin{array}{l}\text { Accounts belonging to university faculty or those involved in } \\
\text { educational research }\end{array}$ & Research \\
\hline $\begin{array}{l}\text { Educational } \\
\text { Institution }\end{array}$ & Accounts associated with schools or government bodies & Research \\
\hline $\begin{array}{l}\text { Educational } \\
\text { Organization }\end{array}$ & $\begin{array}{c}\text { Accounts associated with companies or non-profit } \\
\text { organizations affiliated with education (or individuals in } \\
\text { these companies or organizations) }\end{array}$ & Research \\
\hline $\begin{array}{l}\text { Education- } \\
\text { Connected }\end{array}$ & $\begin{array}{l}\text { Accounts belonging to persons concerned with education but } \\
\text { whose specific role is unidentified or does not fall in one of } \\
\text { the other categories }\end{array}$ & Others \\
\hline Media & $\begin{array}{l}\text { Accounts affiliated with media outlets, social media curators, } \\
\text { etc. }\end{array}$ & Others \\
\hline $\begin{array}{l}\text { Hashtag / Chat } \\
\text { Accounts }\end{array}$ & $\begin{array}{l}\text { Accounts affiliated with educational Twitter communities, } \\
\text { such as SETHs or Twitter chats }\end{array}$ & Others \\
\hline Not Clear & $\begin{array}{l}\text { Accounts that did not fall into any of the above categories or } \\
\text { could not be coded }\end{array}$ & Others \\
\hline
\end{tabular}




\section{Table S4}

Descriptive Statistics for \#NGSSchat Conversation Networks

\begin{tabular}{cc}
\hline Statistic & Mean $(S D)$ \\
\hline \multicolumn{2}{c}{ Transactional Conversations } \\
Density & 0.025 \\
Mean $(S D)$ in-degree centrality & $5.26(10.89)$ \\
Substantive (Sense-making and Transformational) & Conversations \\
Density & 0.21 \\
Mean $(S D)$ in-degree centrality & $25.58(59.30)$ \\
\hline
\end{tabular}




\section{Table S5}

Post Hoc Comparisons Between Groups for Professional Roles (for Analyses for RQ\#2)

\begin{tabular}{|c|c|c|c|}
\hline Group & $\begin{array}{l}\text { Hypothesis } \\
\text { (Post Hoc } \\
\text { Comparison) }\end{array}$ & $\beta(S E)$ & Conversation \\
\hline Sender & $\begin{array}{c}\text { Administrator- } \\
\text { Organization }>0\end{array}$ & $\begin{array}{c}0.858(0.647) \\
p=0.907\end{array}$ & Transactional \\
\hline Sender & $\begin{array}{l}\text { Administrator - } \\
\text { Researcher }>0\end{array}$ & $\begin{array}{c}-0.259(0.564) \\
p=0.327\end{array}$ & Transactional \\
\hline Sender & $\begin{array}{l}\text { Administrator- } \\
\text { Teacher }>0\end{array}$ & $\begin{array}{c}0.284(0.367) \\
p=0.782\end{array}$ & Transactional \\
\hline Sender & $\begin{array}{l}\text { Organization - } \\
\text { Researcher }>0\end{array}$ & $\begin{array}{c}-1.116(0.754) \\
p=0.069\end{array}$ & Transactional \\
\hline Sender & $\begin{array}{l}\text { Organization - } \\
\text { Teacher }>0\end{array}$ & $\begin{array}{c}-0.574(0.625) \\
p=0.183\end{array}$ & Transactional \\
\hline Sender & $\begin{array}{l}\text { Researcher - } \\
\text { Teacher }>0\end{array}$ & $\begin{array}{c}0.542(0.547) \\
p=0.846\end{array}$ & Transactional \\
\hline Receiver & $\begin{array}{c}\text { Administrator- } \\
\text { Organization }>0\end{array}$ & $\begin{array}{c}0.183(0.392) \\
p=0.681\end{array}$ & Transactional \\
\hline Receiver & $\begin{array}{l}\text { Administrator - } \\
\text { Researcher }>0\end{array}$ & $\begin{array}{c}-0.433(0.36) \\
p=0.114\end{array}$ & Transactional \\
\hline Receiver & $\begin{array}{l}\text { Administrator- } \\
\text { Teacher }>0\end{array}$ & $\begin{array}{c}0.218(0.238) \\
p=0.819\end{array}$ & Transactional \\
\hline Receiver & $\begin{array}{l}\text { Organization - } \\
\text { Researcher }>0\end{array}$ & $\begin{array}{c}-0.616(0.473) \\
p=0.09\end{array}$ & Transactional \\
\hline Receiver & $\begin{array}{l}\text { Organization - } \\
\text { Teacher }>0\end{array}$ & $\begin{array}{c}0.035(0.382) \\
p=0.536\end{array}$ & Transactional \\
\hline Receiver & $\begin{array}{l}\text { Researcher - } \\
\text { Teacher }>0\end{array}$ & $\begin{array}{c}0.651(0.347) \\
p=0.968\end{array}$ & Transactional \\
\hline Sender & $\begin{array}{c}\text { Administrator- } \\
\text { Organization }>0\end{array}$ & $\begin{array}{c}1.31(0.658) \\
p=0.978\end{array}$ & Substantive \\
\hline Sender & $\begin{array}{l}\text { Administrator - } \\
\text { Researcher }>0\end{array}$ & $\begin{array}{c}0.191(0.518) \\
p=0.64\end{array}$ & Substantive \\
\hline
\end{tabular}




$\begin{array}{cccc}\text { Sender } & \text { Administrator- } & 0.507(0.326), & \text { Substantive } \\ & \text { Teacher }>0 & p=0.945 & \\ \text { Sender } & \text { Organization }- & -1.119(0.744), & \text { Substantive } \\ & \text { Researcher }>0 & p=0.066 & \\ \text { Sender } & \text { Organization }- & -0.803(0.632), & \text { Substantive } \\ & \text { Teacher }>0 & p=0.099 & \\ \text { Sender } & \text { Researcher }- & 0.316(0.483), & \text { Substantive } \\ & \text { Teacher }>0 & p=0.746 & \\ \text { Receiver } & \text { Administrator- } & 0.795(0.616), & \text { Substantive } \\ & \text { Organization }>0 & p=0.903 & \\ \text { Receiver } & \text { Administrator }- & 0.066(0.495), & \text { Substantive } \\ & \text { Researcher }>0 & p=0.541 & \\ \text { Receiver } & \text { Administrator- } & 0.619(0.307), & \text { Substantive } \\ & \text { Teacher }>0 & p=0.976 & \\ \text { Receiver } & \text { Organization }- & -0.73(0.694), & \text { Substantive } \\ & \text { Researcher }>0 & p=0.148 & \\ \text { Receiver } & \text { Organization }- & -0.176(0.59), & \text { Substantive } \\ & \text { Teacher }>0 & p=0.379 & \\ & \text { Researcher }- & 0.554(0.461), & \\ & \text { Teacher }>0 & p=0.882 & \\ & & & \\ & & & \end{array}$

Note. The other professional role served as the reference group; comparisons between the effects of being in the other role and any other professional role can be interpreted from the results presented in Table 5. The $\beta$ coefficients here are not the Incident Rate Ratios reported in Tables 5 and 6 , which are the exponentiated $\beta$ coefficients. 


\section{Table S6}

Post Hoc Comparisons Between Groups for Professional Roles (for Analyses for RQ \#3)

\begin{tabular}{cc}
\hline Post Hoc Comparison & $\beta(S E)$ \\
\hline Organization - Administrator & $-2.17(0.07), p<.001$ \\
Researcher - Administrator & $-0.99(0.05), p<.001$ \\
Teacher - Administrator & $0.05(0.05), p=.328$ \\
Researcher - Organization & $1.18(0.07), p<.001$ \\
Teacher - Organization & $2.23(0.07), p<.001$ \\
Teacher - Researcher & $1.05(0.052), p<.001$ \\
\hline
\end{tabular}

Note. The other professional role served as the reference group; comparisons between the effects of being in the other role and any other professional role can be interpreted from the results presented in Table 6 . The $\beta$ coefficients here are not the Incident Rate Ratios reported in Tables 5 and 6 , which are the exponentiated $\beta$ coefficients. 